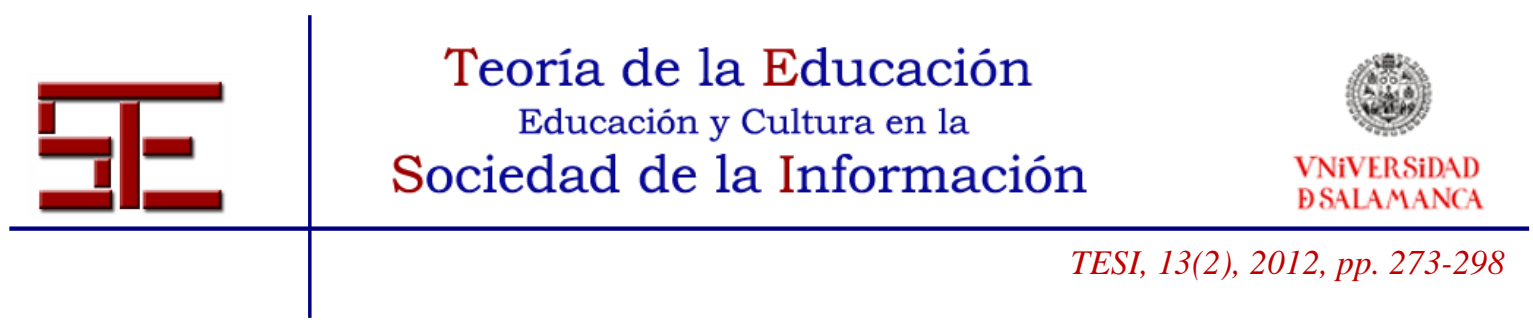

\title{
EL SUJETO NEURONAL: APORTACIONES PARA UNA PEDAGOGÍA DE LA POSIBILIDAD
}

Resumen: Las investigaciones sobre el funcionamiento y desarrollo del cerebro están contribuyendo al surgimiento de una nueva comprensión de la cognición y del aprendizaje. La comprensión de los mecanismos neuronales que determinan la cognición y el aprendizaje -y que subyacen a la formación de la conciencia-, así como la relación entre cognición y emociones, y entre genética y entorno, tienen importantes implicaciones educativas (OECD, 2007, 2010; Gonçalves, 2009). Estos conocimientos conducen a nuevas perspectivas sobre el sujeto de la educación que nos permiten superar viejas dicotomías: razón/emociones, biología/cultura, cuerpo/mente, genética/entorno. El sujeto es «bio-psico-social», una construcción bio-antropológica: es bimodal (Asensio, García Carrasco, Núñez Cubero, Larrosa, 2006; García Carrasco, 2007) o multimodal (Smith, 2005), es Sapiens y Demens (Morin, 1999). Es lo que está entre (Nunes, 2002).

En este artículo se analizan las implicaciones que las teorías emergentes de las neurociencias cognitivas tienen para la comprensión del sujeto de la educación. Dicho sujeto se caracteriza de acuerdo con su plasticidad, multidimensionalidad y capacidad narrativa, entendida como un concepto fundamental relacionado con la construcción de su identidad, y se reflexiona sobre las implicaciones educativas de esta perspectiva en el ámbito de una pedagogía de la posibilidad encuadrada en el marco de la complejidad.

Palabras clave: neurociencias cognitivas; educación; cognición; plasticidad neuronal; identidad.

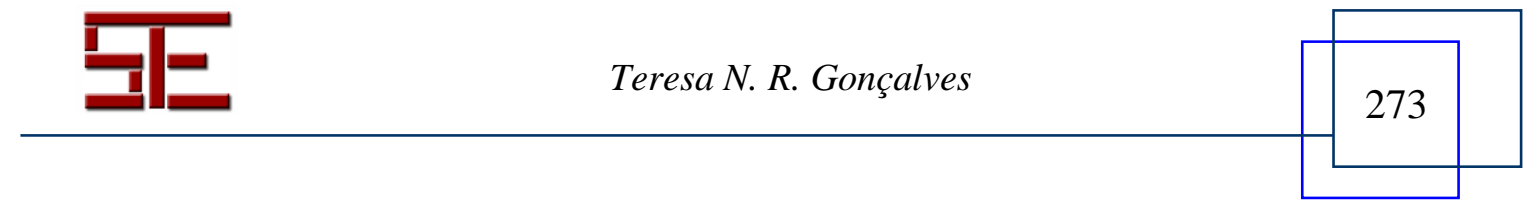




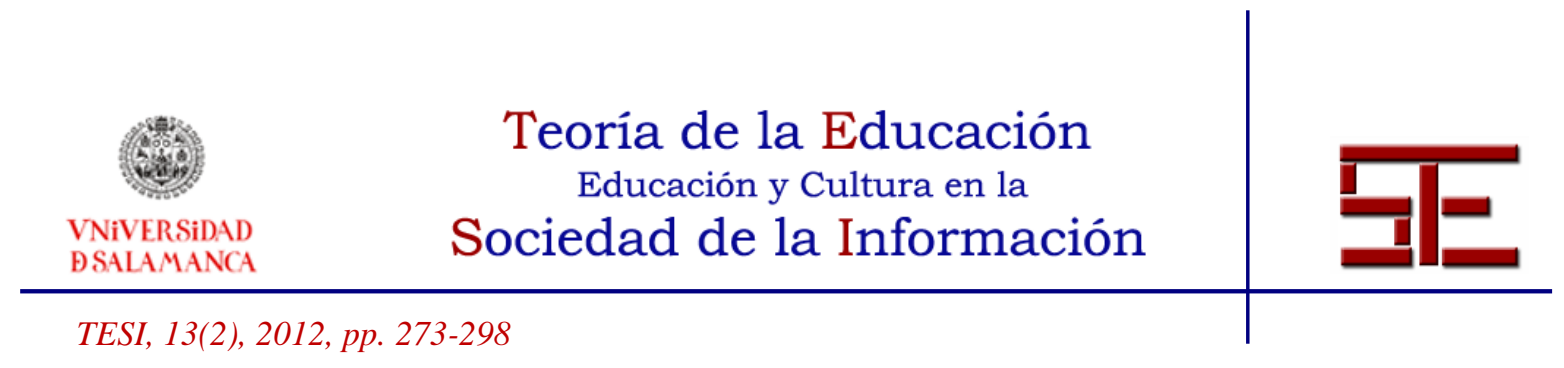

\title{
THE NEURAL SUBJECT. CONTRIBUTIONS TO A PEDAGOGY OF POSSIBILITY
}

\begin{abstract}
Research on brain functioning and development is contributing for the emergence of new understandings of cognition and learning. The understanding of the neural mechanisms determining cognition and learning and underlying consciousness formation, the relation between cognition and emotions, genetic and environment, have important implications for education (OECD, 2002, 2007; Gonçalves, 2009). This emergent body of knowledge refers to a new perspective about the human subject which may allow us to surpass old dichotomies: reason/emotions; nature/nurture; body/mind; genetics/environment. The subject is bio-psycho-social, he is a bio-anthropological construction: he is bimodal (Asensio, García Carrasco, Núñez Cubero, 2006; García Carrasco, 2007) or multimodal (Smith, 2005), Sapiens and Demens (Morin, 1999). As stated by Nunes (2002), he is what is in between.
\end{abstract}

In this paper I will analyse the implications of emergent theories in educational neurosciences for the understanding of the subject of education. The human subject will be characterized considering: his plasticity, his multidimensionality and his narrative capacity. I will analyse the educational implications of this perspective within the framework of a pedagogy of possibility (Gonçalves, 2008), supported in a complexity theory approach.

Keywords: cognitive neurosciences; education; cognition; neural plasticity; identity

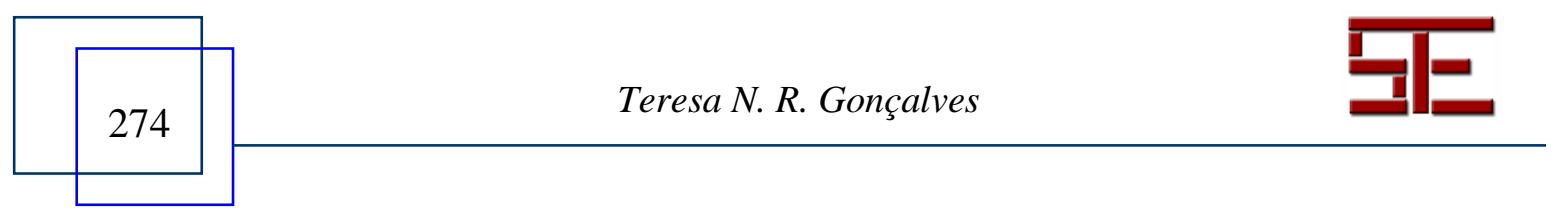




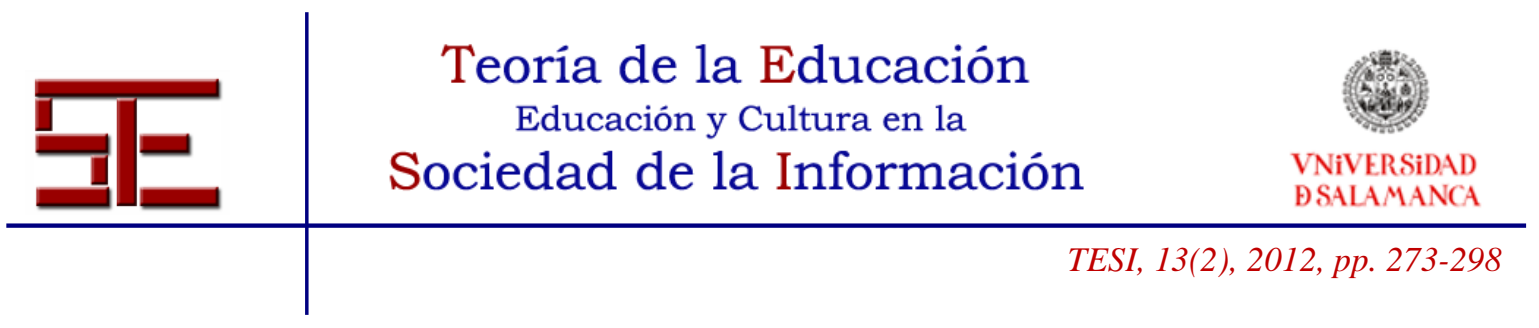

\section{EL SUJETO NEURONAL: APORTACIONES PARA UNA PEDAGOGÍA DE LA POSIBILIDAD}

Fecha de recepción: 20/09/2011; fecha de aceptación: 20/10/2012; fecha de publicación: 26/07/2012

Teresa N. R. Gonçalvez

tprg@fct.unl.pt

UIED/FCT/Universidade Nova de Lisboa

\section{1.- INTRODUCCIÓN}

Las investigaciones sobre el cerebro y su desarrollo en el campo de las neurociencias cognitivas, la orientación de la biología evolutiva hacia una perspectiva ecológica, compleja e integrada del desarrollo de los seres vivos y su relación con el entorno (Lewontin, 1998), y la creciente conciencia de la importancia que poseen los nuevos conocimientos para la tarea educativa (OCDE, 2002, 2007, 2010; Gonçalves, 2010) están contribuyendo a la aparición de una nueva perspectiva sobre el sujeto de la educación. El entendimiento neurológico de la mente y la consciencia en cuanto sede de la cognición y de la personalidad, abre un conjunto de posibilidades y horizontes de reflexión sobre el ser humano y su devenir cuyas implicaciones y diferentes dimensiones no pueden ser ignoradas. El entendimiento neuro-bio-fisiológico de la consciencia y del ser y hacer humanos posibilita un nuevo entendimiento del sujeto, de la cognición y de la educación. La pregunta sobre la dimensión y naturaleza de esas posibilidades corresponde, en gran medida, a la cuestión planteada por Malabou (2004, 135): «¿Qué nuevos horizontes abren los nuevos cerebros, los nuevos teóricos del cerebro?»; principalmente, en lo que se refiere a un nuevo entendimiento del sujeto de la educación.

La comprensión de los mecanismos neuronales que determinan la cognición y el aprendizaje, y que subyacen a la formación de la consciencia, la relación entre cognición y emociones y entre genética y entorno, tienen importantes implicaciones educativas (OECD, 2007, 2010; Gonçalves, 2010). Estos conocimientos conducen a nuevas perspectivas sobre el sujeto de la educación que nos permiten superar viejas dicotomías: razón/emociones, biología/cultura, cuerpo/mente, genética/entorno.

En gran medida, la reflexión de Angel Riviére (1987) sobre el sujeto de la psicología cognitiva y su crítica del paradigma computacional puede ser ampliada y

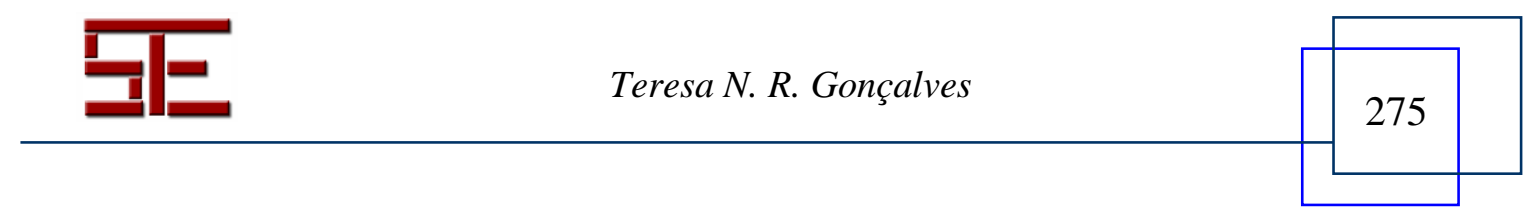




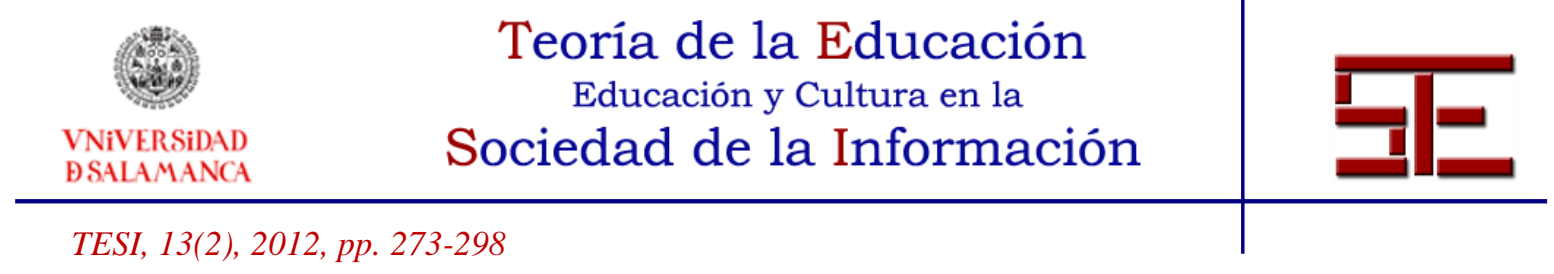

complementada por los nuevos conocimientos que aportan las neurociencias cognitivas. Según el autor, «a medida que ha crecido, el sujeto de la psicología cognitiva se ha hecho menos lógico, más difícil de formalizar; quizá, más impredecible y divertido también» (Riviére, 1987, 28). Esta nueva visión del sujeto permitiría distanciarnos de la «imagen acromática del sujeto cognitivo en las formulaciones formalistas tradicionales, tanto del núcleo paradigmático del procesamiento de la información como del de Piaget y Chomsky» (Riviére, 1987, 87). Al alejarnos de las perspectivas más tradicionales de la psicología cognitiva y del desarrollo -y de esas imágenes de formas sin contenidos, así como de un sujeto sin más objetos que las cosas o tareas, delineando figuras sin contexto -, las perspectivas emergentes de las neurociencias cognitivas evidencian la necesidad de analizar y explorar otros escenarios que permitan situar al sujeto y a su desarrollo en un horizonte afectivo interpersonal, social y cultural en el que ocurre y se sitúa su experiencia.

El sujeto posee una consciencia que se forma en la relación y en el contacto social, en una interacción entre factores genéticos y epigenéticos que le sitúan, simultáneamente, como producto y productor de su propia historia, lejos del modelo estándar de sujeto cognitivo supuestamente universal que ofrecen las teorías formalistas. El sujeto es biopsico-social, es una construcción bio-antropológica: es bimodal (Asensio, García Carrasco, Núñez Cubero, Larrosa, 2006; García Carrasco, 2007) o multimodal (Smith, 2005), es Sapiens y Demens (Morin, 1999), es lo que está entre (Nunes, 2002).

En este artículo se analiza la nueva perspectiva del sujeto emergente de las ciencias cognitivas; principalmente, de las neurociencias cognitivas. Dicho sujeto se caracteriza de acuerdo con su: 1) plasticidad; 2) multidimensionalidad, y 3) capacidad narrativa, entendida como un concepto fundamental relacionado con la construcción de su identidad, y se reflexiona sobre las implicaciones educativas de esta perspectiva en el ámbito de una pedagogía de la posibilidad encuadrada en el marco de la complejidad.

\section{2.- PLASTICIDAD}

La plasticidad es un concepto complejo -y, en cierta medida, polisémico- cuya utilización e implicaciones trascienden los límites de la ciencia, y plantea cuestiones educativas, sociales e, incluso, políticas. La centralidad del concepto de plasticidad en la investigación sobre el cerebro, las implicaciones que tiene para la comprensión del papel del aprendizaje, de la evolución y del desarrollo, así como el aporte que representa para un nuevo entendimiento del sujeto, tienen consecuencias que van más allá de un

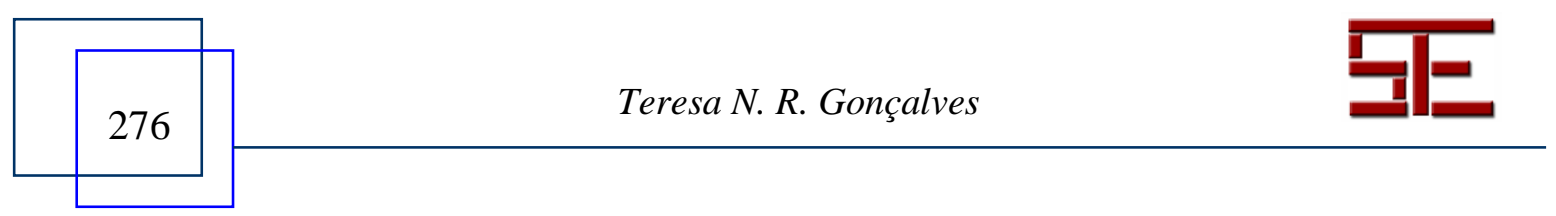




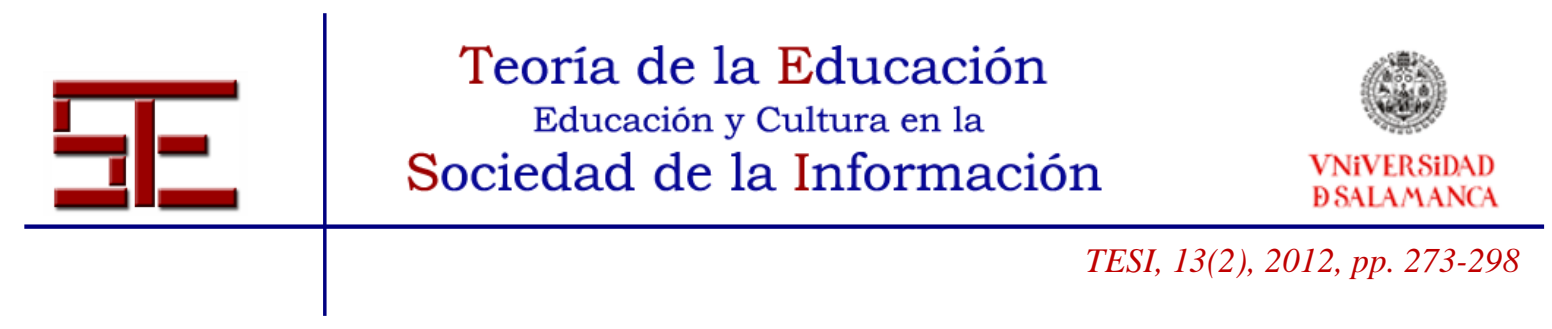

entendimiento meramente científico de los procesos de funcionamiento y desarrollo neuronal. Por eso, se propone un análisis que contemple dos vertientes: el entendimiento neuronal de la consciencia y del funcionamiento cerebral $-\mathrm{O}$ sea, sus características e implicaciones más propiamente científicas-, y sus implicaciones y acepciones educativas, sociales y políticas. Se intentará contestar a las siguientes cuestiones: ¿Qué representa un entendimiento del sujeto como plástico? ¿Qué implicaciones tiene tal concepto para la teoría de la educación?

\section{1.- Plasticidad Neuronal}

La plasticidad instaura un nuevo orden neuronal que define al cerebro como un órgano plástico y mutable ${ }^{1}$ En términos neuronales, la plasticidad involucra a distintos factores, niveles y condicionantes, cuyas características e implicaciones principales se considera podrían estar organizadas de la siguiente forma:

- El cerebro tiene la capacidad de cambiar, adaptarse y aprender a lo largo de toda la vida. La plasticidad subyace al aprendizaje.

- El cerebro cambia como respuesta a la estimulación ambiental, lo que significa que no está completamente determinado desde el inicio. Esos cambios están determinados por la interacción de factores genéticos y epigenéticos.

- La plasticidad implica periodicidad en la medida en que existen períodos sensibles, o «ventanas de oportunidad», que favorecen o dificultan determinados cambios.

- La plasticidad está sujeta a límites relacionados con el funcionamiento y organización cerebral (neurogénesis y apoptosis).

- El funcionamiento del cerebro es plástico, y su organización es integrada.

- El uso que se hace del cerebro es determinante para su desarrollo, para su «construcción».

De acuerdo con estos principios, la plasticidad neuronal se asienta en la capacidad constante de cambio y adaptación del cerebro a las exigencias del medio y de acuerdo con las experiencias de aprendizaje. Sin embargo, lejos de ser una plasticidad a toda prueba, existen limitaciones y condicionantes, de orden temporal y espacial, relacionados con factores genéticos y contextuales configurados tanto por la dimensión biológica como por la experiencia vital de los individuos. La plasticidad resulta de la conjugación entre posibilidades y límites biológicos, así como de posibilidades y límites relacionados con la mencionada experiencia vital, tanto individuales como sociales; o sea, subjetivos e intersubjetivos. En este sentido, combina posibilidad con oportunidad ${ }^{2}$.

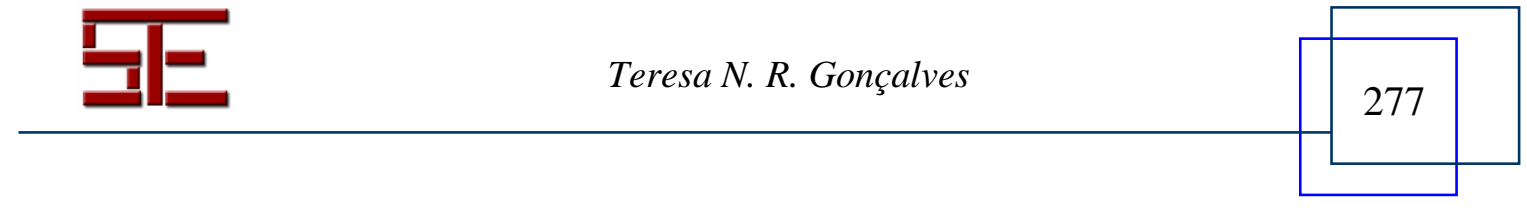




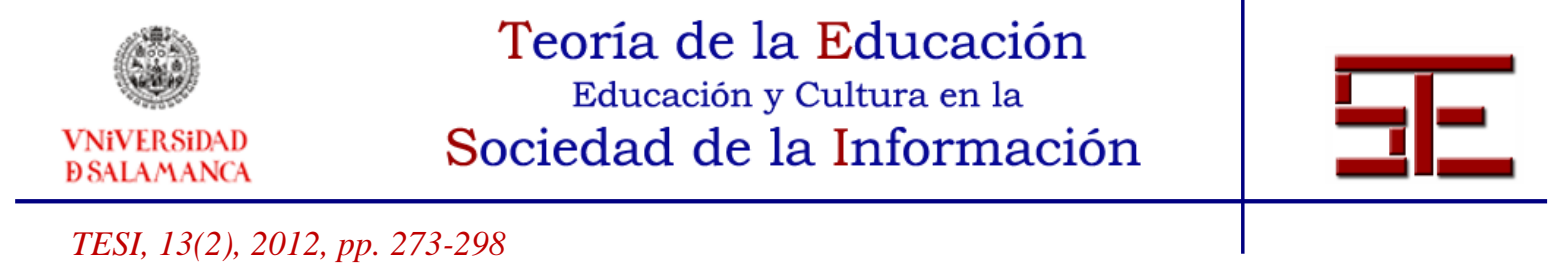

Más allá de la dimensión biológica o neuronal, el concepto «plasticidad» expresa la tensión esencial entre la apertura y el cierre del ser humano, patente en el propio desarrollo del cerebro. En el cerebro existen elementos de rigidez y de plasticidad que se conjugan para facilitar el aprendizaje y el desarrollo. La plasticidad tiene una doble dimensión: por una parte, está condicionada; sin embargo, no está en absoluto determinada por la genética. Por otra, representa la apertura a la experiencia, a la posibilidad. La distinción entre la plasticidad experiencia-expectante $e^{3}$ y la plasticidad experiencia-dependiente ${ }^{4}$ corresponde a la tensión entre plasticidad y periodicidad; la plasticidad tiene sus propios límites.

Entendida con el sentido de «ventanas de oportunidad», la periodicidad se postula no como restricción, sino como apertura de posibilidades. El cerebro no funciona ni con la rigidez que antes se le suponía ni con una flexibilidad a toda prueba. A pesar de su apertura a las influencias del medio, es su estructura la que define esa relación, determinando el tipo de estímulos al que puede reaccionar en un determinado momento. Es a partir de estas estructuras que reacciona al medio, a sus exigencias y solicitudes.

Existen aspectos universales del desarrollo del cerebro - por eso, se puede hablar de estadios (Goldberg, 2006) -, pero otros son altamente individuales. La diferenciación funcional aumenta a lo largo del desarrollo, pues se hace posible un mayor número de trayectorias viables, y la variabilidad se torna considerable y progresivamente más destacada. La proliferación y el refuerzo sináptico, junto con la poda sináptica, son las dos fuerzas que esculpen las redes neuronales y definen el desarrollo. Estos procesos son instrumentos de la auto-organización que explica las diferencias individuales, y estas -a pesar de depender de algunas condiciones iniciales- son principalmente producto de la experiencia, que es elaborada y reelaborada en el cerebro. El carácter recursivo (Lewis, 2005) de las alteraciones sinápticas muestra la tendencia para la repetición que está en la base de la formación de linajes de estandarización individual; una repetición que, progresivamente, elabora sus propios temas emergentes.

Las posibilidades y límites que implica la plasticidad neuronal no son más que el reflejo de las restricciones, condiciones o límites a los que están sujetas la naturaleza y existencia humana, y pueden ser constatados en diferentes niveles y dimensiones. García Carrasco $(2007,212)$ se refiere al cuerpo como «[...] la primaria fuente de posibilidad, la primaria fuente de restricción, lo que primero pone condiciones». De la misma forma, otros elementos se conjugan para limitar y lograr vías de desarrollo. El mismo autor añade: «Las condiciones de la naturaleza que llegan al individuo son el aire

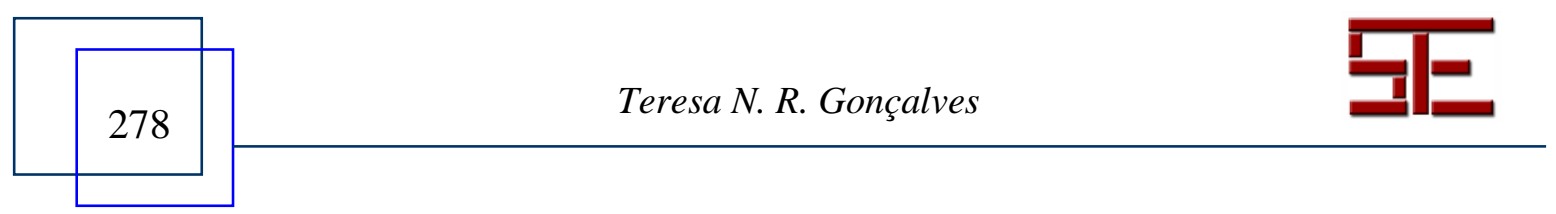




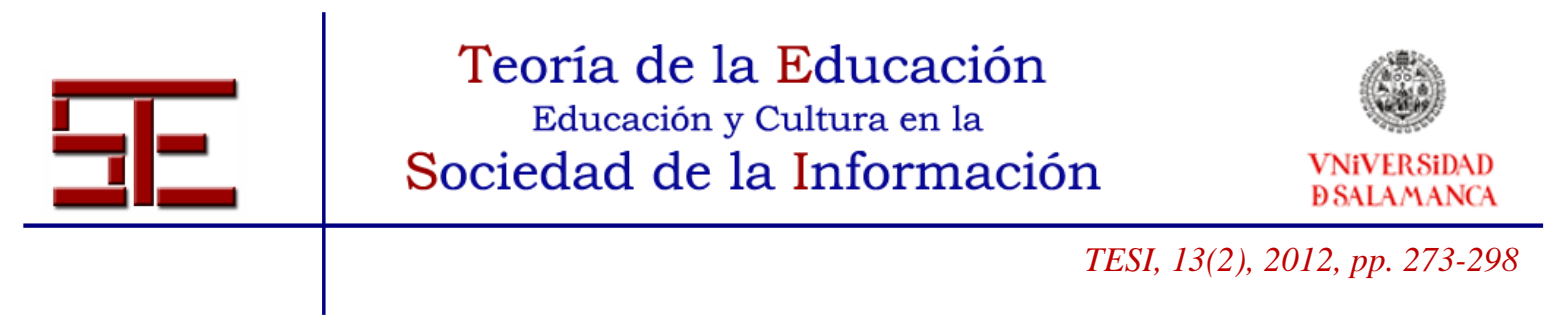

que respira la condición humana» (García Carrasco, 2007, 216). El cuerpo funciona simultáneamente como frontera y como ventana abierta al mundo, como una condición de posibilidad de contacto que determina, al mismo tiempo, los límites de esa relación. Existe un paralelismo entre la plasticidad neuronal y la vida humana en la medida en que, como aquella, también esta se desarrolla y construye entre los límites y las posibilidades que ofrece la genética y los límites y posibilidades que brinda la cultura. «Cada individuo posee, por naturaleza, su propio límite y su propio margen de calidad de vida posible» (García Carrasco, 2007, 191). De esta forma, la idea de periodicidad y de límites es tan fundamental para la plasticidad como lo es la de apertura de posibilidades. En el cuerpo y en el cerebro convergen la naturaleza y la cultura, la vida y la mente, «[...] porque el organismo humano está atravesado por infinidad de tramas vitales cuyos hilos se retrotraen por toda la historia de la vida, y porque las condiciones que el organismo aporta a la vida marcan límites y trayectorias a la historia experiencial de la mente» (García Carrasco, 2007, 233).

La plasticidad también se manifiesta en el cerebro en varios niveles, y es de diversos tipos: la capacidad para formar nuevas conexiones interneuronales, la formación de nuevas espinas dendríticas y de nuevos «botones» sinápticos, y la redistribución o asignación de nuevas funciones. La plasticidad es el concepto fundamental que explica la organización del cerebro, el funcionamiento de las neuronas, el origen de los estados mentales, los procesos de conocimiento y de aprendizaje, así como las diferencias entre los cerebros una vez que «naturaleza, crianza y aprendizaje no pueden dejar de hacer único cada cerebro y trabajar en progreso a lo largo de toda la vida» (OCDE, 2002, 34). Se entiende que el concepto «plasticidad» puede aplicarse a diversos ámbitos educativos, sociales y culturales. Permite, además, sobrepasar el dualismo psico-físico que separa el psíquico del orgánico, el espiritual del corporal, el biológico del cultural, y que ha apartado durante mucho tiempo a la psicología de la biología y de la neurología. Así, estos conocimientos están en el origen del surgimiento de nuevas disciplinas que resultan de la convergencia entre distintas ciencias, como es el caso de la neurociencia cognitiva $^{5}$. Explican la complejidad del ser humano y permiten plantear la cuestión del sujeto en nuevos términos de acuerdo con la reconceptualización del cerebro como plástico y, posteriormente, del individuo como sujeto de la plasticidad. Mario Bunge (1989, 18-19) afirma: «La plasticidad del tejido nervioso es una propiedad capital del mismo y, en mi opinión, la clave del psiquismo [...]. La plasticidad conductual no es sino una manifestación de la plasticidad neuronal». Como establece en una obra posterior (Bunge, 2004), la plasticidad también puede ser transpuesta al campo social. Puede, por tanto, ser pensada en diferentes niveles o dimensiones.

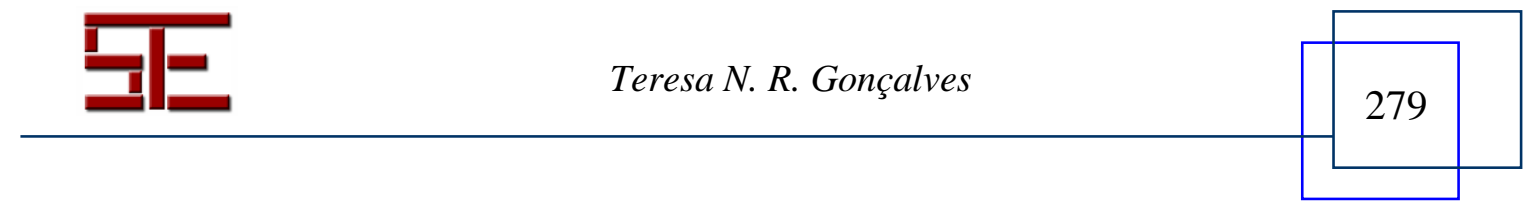




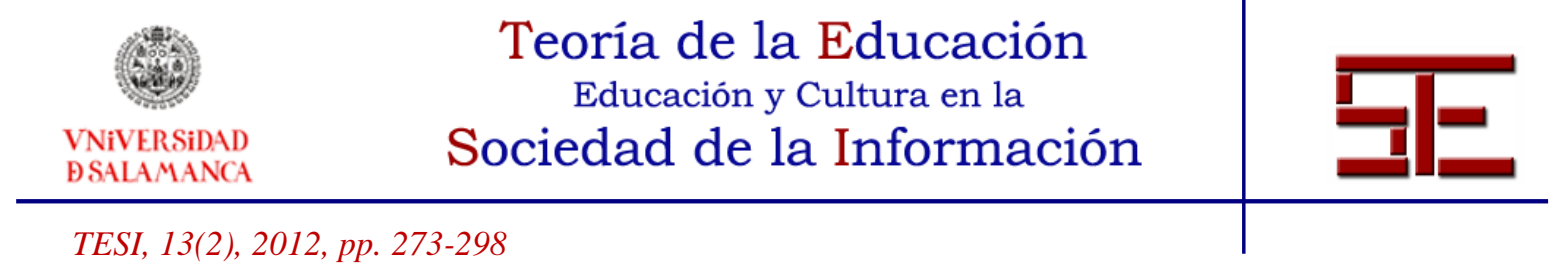

Asimismo, la plasticidad sustenta la perspectiva del cerebro como base de la mentehipótesis biológica o materialista de la mente ${ }^{6}-$. Todos los procesos mentales son cerebrales; sin embargo, la mente no se reduce al cerebro, y tales procesos ocurren en un contexto natural y social. Por eso, son complejos y multidimensionales. El ser humano como sistema no puede ser entendido sin que se entiendan antes los diferentes aspectos o dimensiones que lo constituyen y que atraviesan una serie de niveles de organización que van desde el nivel químico al social. La hipótesis biológica de la mente y de la consciencia no es reductora si se enfoca desde una perspectiva sistémica y desde el reconocimiento de que los procesos mentales poseen especificidades que los distinguen de otras funciones corporales.

La educación ha de ser pensada teniendo en cuenta la capacidad plástica del cerebro y las características y factores que caracterizan su desarrollo, asumiendo que el sujeto de la plasticidad es un sujeto complejo, y que su desarrollo funciona en varios niveles y está determinado por distintos factores. Entre las posibilidades y los límites de su condición plástica, el sujeto construye su «yo»y, con él, su cerebro. Esa construcción se da en el marco de la relación genética/entorno que configura posibilidades y límites, y define oportunidades. En lo que se refiere a los seres humanos, dicha construcción se da entre autonomía o libertad y adaptación, entre la adaptación al medio y la transformación del ambiente en el que viven (Asensio, 1997). La autonomía del sujeto reside tanto en su plasticidad neuronal como en su plasticidad conductual y social. Está sustentada por la plasticidad genética, que subyace a la capacidad de aprender, asimilar y trasformar un patrimonio cultural acumulado a lo largo del tiempo. Adaptación y emancipación son, como afirma Asensio (1997), consustanciales con la educación.

«Educar no debiera ser entendido por ello como un mero conformar de las personas a los modos de hacer y pensar de un cierto colectivo humano, sino también como una actividad orientada a potenciar sus aptitudes para interpretar y transformar la realidad social de la que forman parte; o sea, para promover la autonomía». (Asensio, 1997, 44)

En términos educativos, descuidar esta dinámica adaptación-evolución a la que se encuentran sometidos todos los organismos en su relación con el entorno - tal y como ha ocurrido frecuentemente en nuestros sistemas educativos- significa ignorar la complejidad de los sujetos y reducir las oportunidades de realización de sus posibilidades. El sujeto construye su identidad entre determinismo y libertad, según una dialéctica histórica vital desde la que se van configurando, concretizando y descartando

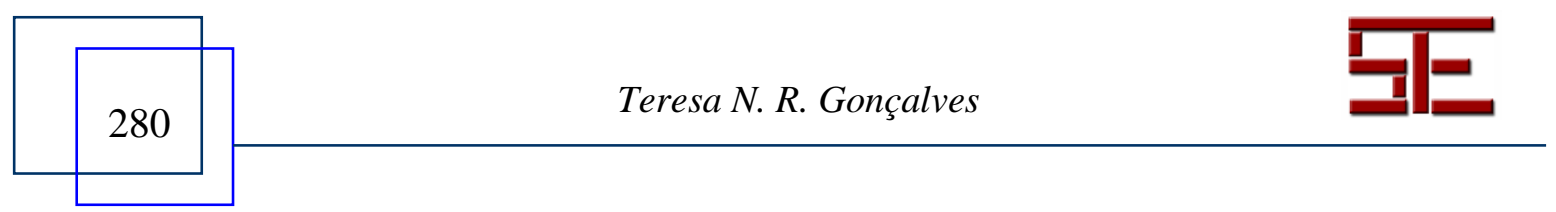




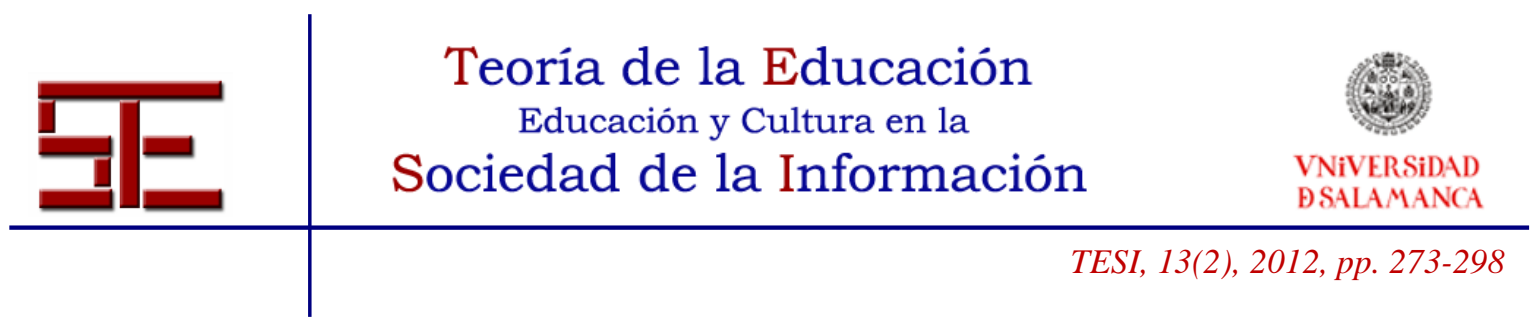

posibilidades y oportunidades de desarrollo, en una constante necesidad de búsqueda y producción de sentido de la existencia y vivencia subjetiva e intersubjetiva.

En este sentido, la centralidad del concepto «plasticidad» en la construcción por parte del sujeto de su identidad -más allá de las características e implicaciones neuronales y desde una perspectiva compleja y crítica- tiene implicaciones tanto pedagógicas como éticas, estéticas y políticas (Malabou, 2004) que se deben considerar.

\section{2.- Educabilidad y Plasticidad}

La posibilidad de crear un puente entre los nuevos conocimientos sobre el cerebro y la educación, y de pensar las posibles implicaciones y aplicaciones de dichos conocimientos a la práctica educativa, supone clarificar la relación que existe entre los conceptos originarios de ambos campos del saber. Por una parte, se considera la centralidad del concepto «plasticidad» en el dominio de las neurociencias cognitivas y, por otra, la centralidad del concepto «educabilidad» en el ámbito de las ciencias de la educación; principalmente, en la teoría de la educación. En lo que se refiere a estos conceptos, y a sus relaciones e implicaciones, se trata de lo que Bunge (2004) ha denominado «conceptos-puente»7. Tales conceptos pueden permitir pensar de una forma más detallada y fundamentada la posible y, añadiría, necesaria convergencia entre ciencias del cerebro y ciencias de la educación.

Como refiere Asensio (1997), el concepto «educabilidad» ha sido entendido tanto como sinónimo de plasticidad cerebral -o de capacidad para aprender- como un concepto casi metafísico que representa la especial disposición de los individuos para ser educados. En este artículo, se entiende que la plasticidad soporta y subyace a la educabilidad: si el cerebro no fuera plástico, el aprendizaje sería imposible. Si el sujeto no fuera educable, no tendría la oportunidad de incorporarse a una determinada cultura, de aprender, de construir y de transformarse, transformando también el mundo en el que vive. Sin educabilidad, el sujeto no podría lograr las promesas o posibilidades que su plasticidad neuronal le ofrece. Es necesario tener en cuenta las características del cerebro, entendido como plástico, en el sentido de promover, potenciar y concretizar plenamente la educabilidad del ser humano.

La capacidad de aprender bajo la influencia de terceros está fundamentada en la plasticidad de las estructuras cerebrales, pero, más allá de ellas, representa la posibilidad de incorporación cultural de los individuos a través de la comunicación y de procesos

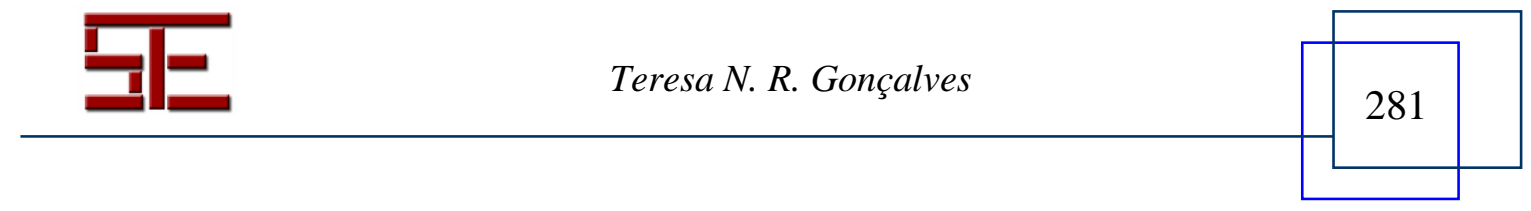




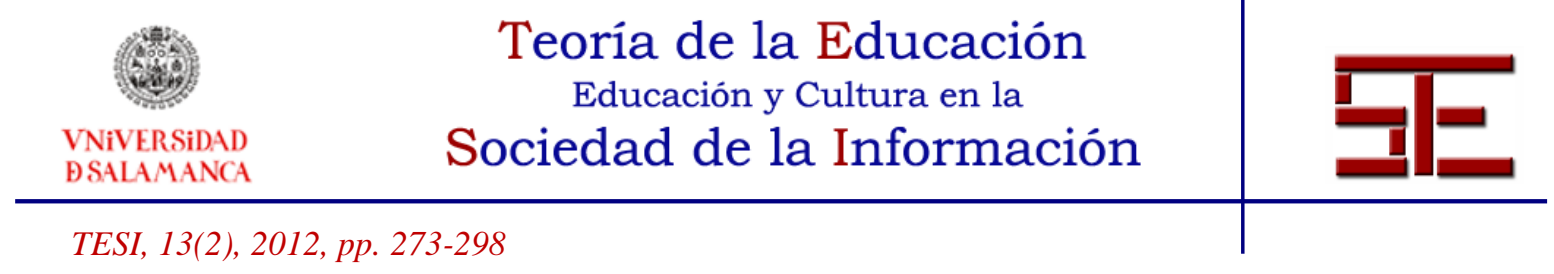

intersubjetivos. Implica la capacidad de aprender y la capacidad de enseñar, pero también la capacidad de apropiarse, transformar y expandir la experiencia y el patrimonio social y cultural acumulado por las generaciones anteriores.

Tanto el concepto de plasticidad como el de educabilidad son inherentes a la perspectiva de la complejidad humana, compatibles y consistentes con la compleja visión sistémica del ser humano y de su desarrollo. Demuestran la naturaleza cambiante, compleja e impredecible del ser y del actuar humanos, y manifiestan el horizonte de libertad y de responsabilidad en el que se configura la construcción de la propia identidad. Eso permite pensar en los mencionados conceptos de plasticidad y educabilidad más allá de simplificaciones normalizadoras y reductoras. $\mathrm{Ni}$ la educabilidad representa la posibilidad de moldear a los individuos -en el sentido de sumisión o dulcificación de los mismos-, ni la plasticidad representa una simple capacidad de adaptación pasiva y pacifica; antes bien, se reconoce que contiene posibilidades creadoras y auto-creadoras del cerebro y del sujeto en su relación con el mundo. Es la capacidad de acción libre, sustentada en la voluntad en la construcción del cerebro y del aprendizaje.

La plasticidad -entendida como propiedad neuronal que puede transponerse a los niveles comportamental y social- y la educabilidad - entendida como la capacidad de aprender, enseñar, relacionarse, comunicarse y transformarse del ser humano- son condiciones de posibilidad de la construcción por parte del sujeto de su propia identidad, y se anclan a sus capacidades conscientes y auto-conscientes. La educación debe tener en cuenta las características y posibilidades plásticas del cerebro, de cada cerebro en un momento determinado y de acuerdo con determinadas condiciones.

En la educabilidad, convergen (o, a veces, divergen) las interacciones entre el sustrato psico-biológico que permite el aprendizaje y los estímulos ambientales que lo facilitan o dificultan. La pedagogía, o el acto pedagógico, es el momento en el que esos conceptos o dimensiones se cruzan para permitir el aprendizaje con el fin de alcanzar determinados objetivos. Una reflexión pedagógica centrada en el concepto «plasticidad» será necesariamente una pedagogía de ese encuentro en el que plasticidad orgánica y educabilidad convergen para conseguir determinados fines. «Tanto las cualidades biológicas del sistema cognitivo del ser humano, como las referidas al medio que interactúa con el sujeto, resultan esenciales para el desarrollo de su educabilidad. Esta depende de la realimentación continua que se produce entre uno y otro» (Asensio, 1997, 91).

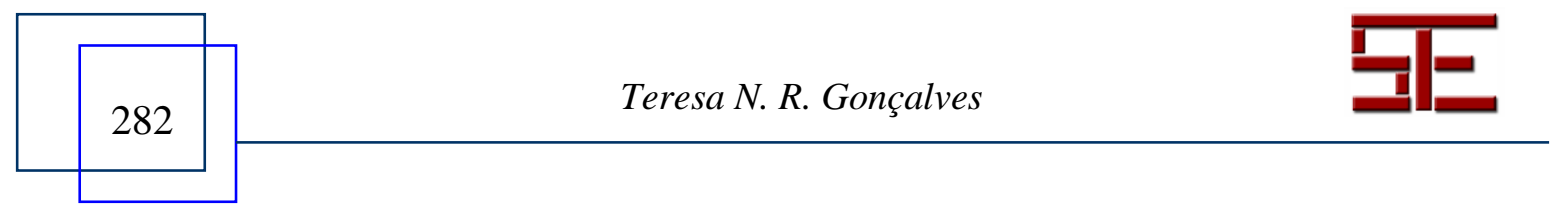




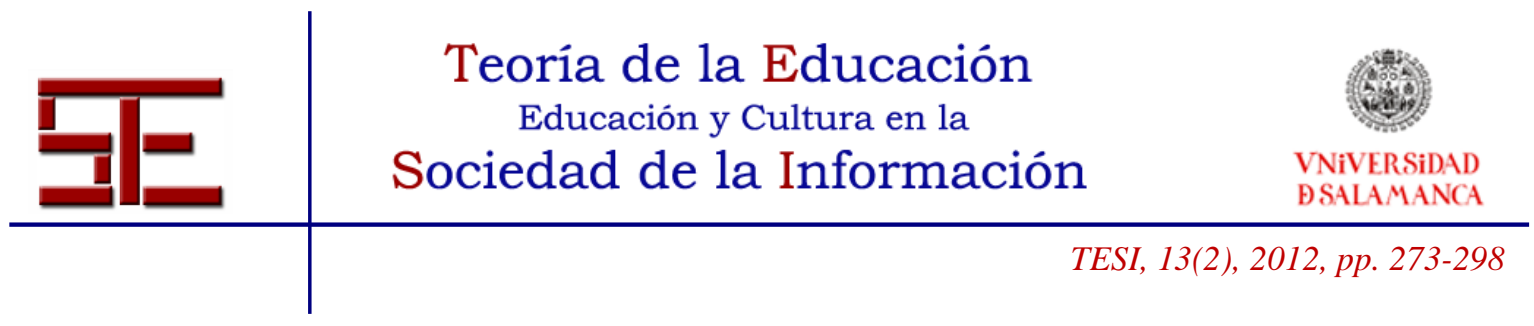

Esa reflexión debe estar sujeta a una interpretación crítica que evite la reducción y que explore las posibilidades que abre al individuo en la construcción de su identidad. Los conceptos «educabilidad» y «plasticidad», fundamentales para la reflexión sobre el sujeto de la educación, deben ser analizados y tematizados críticamente en el sentido de elucidar sus implicaciones éticas, estéticas y políticas (Malabou, 2004).

\section{3.- El Sujeto de la Plasticidad}

El modelo de la plasticidad neuronal se entiende como una herramienta importante y necesaria para entender al sujeto en su complejidad. Dicho entendimiento, más allá de su dimensión neuronal o biológica, plantea cuestiones de naturaleza ética, estética, política -e, incluso, epistemológica- que importa esclarecer. Como afirma Maturana (2003):

«La genética [...] funda un espacio de posibilidades, pero ¿qué se realiza? Depende de la historia del vivir del organismo, por eso es que el vivir no está genéticamente determinado. La genética especifica un espacio de posibilidad gigantesco, y es gigantesco si todos nosotros podemos ser bandidos, ángeles, santos, presidentes de la república, ministros, médicos, profesores, según sea nuestro deseo: como niños». (Maturana, 2003, 44)

En el mismo sentido, García Carrasco $(2007,230)$ dice: «[...] con los recursos de nuestra mente, podemos ser felices o destrozarnos. Es esa condición humana la que debe formar parte del punto de partida de una teoría de la educación y de la cultura para que pueda ser un marco de referencia para todos».

La plasticidad es una cualidad de los cerebros humanos que no es buena ni mala en sí misma (Bernal y Gonçalves, 2006). De ahí, la necesidad de encuadrarla en las dimensiones de la ética, de la estética o de la política: en las formas de vida concretizadas y posibles, en el sentido que los sujetos atribuyen a sus acciones, en sus formas de ser y actuar. Las implicaciones y posibilidades que instaura la plasticidad humana en el campo educativo deben referirse a esta triple dimensión. En este sentido, Malabou (2004) sostiene que la afirmación central de las neurociencias y de las ciencias cognitivas puede ser problemática en lo que respecta a la existencia de una continuidad perfecta entre el neuronal y el mental en la medida en que este no es un postulado estrictamente científico; por el contrario, representa una posición filosófica y epistemológica que hace más problemática esa continuidad. De ahí que la nueva visión que representa tenga elementos que pueden ser de liberación o de sujeción.

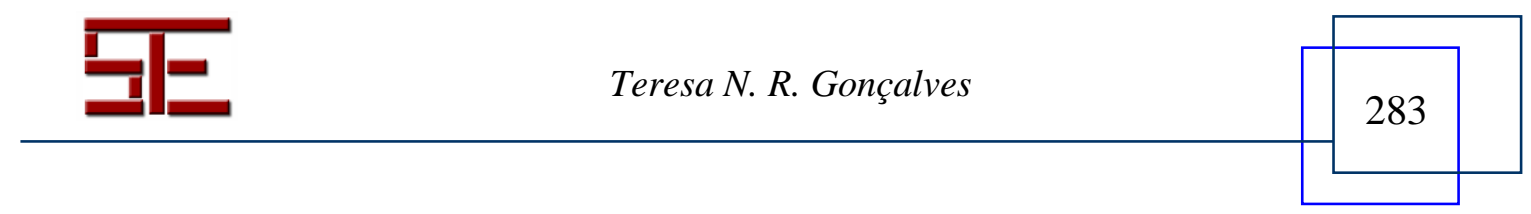




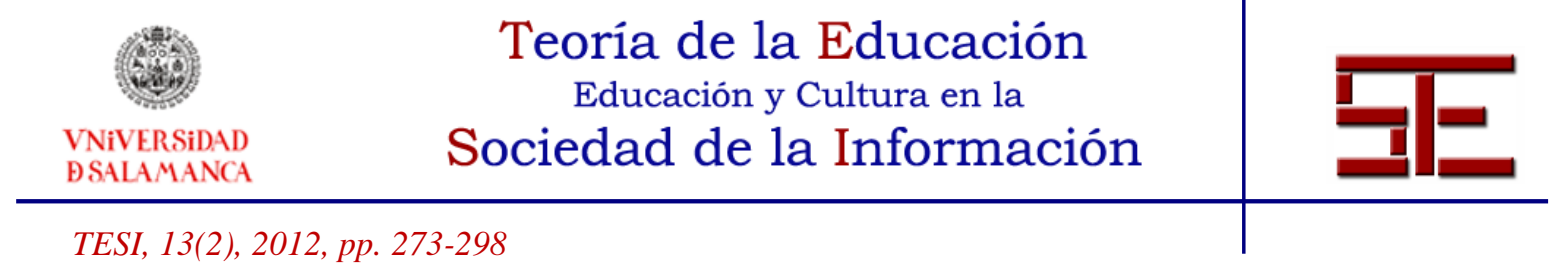

Malabou hace una distinción entre plasticidad y flexibilidad que puede ser útil en este campo. La plasticidad es una instancia creadora y liberadora del sujeto, de su pensar y de su obrar, del proceso de construcción autónoma de sí mismo. La flexibilidad, por su parte, se constituye como un elemento de dominación, de pasividad y docilidad que apela a la sumisión y constante adaptación a un orden económico, social y político establecido, que puede convertirse en darwinismo mental y psicológico con vistas a una cierta idea de eficacia. Confundir plasticidad con flexibilidad puede, entonces, constituir una perversión de la idea misma de plasticidad y de las potencialidades emancipadoras que esta representa desde el inicio; de ahí, la necesidad de deconstruir la relación entre una y otra. «La flexibilidad no ofrece ninguna experiencia de tensión real entre conservación y evolución; al contrario, confunde ambos conceptos en una lógica pura y simple de imitación y actuación, no es creativa. Es reproductiva y normativa» (Malabou, 2004, 146). Sin embargo, hay que reconocer que el enfoque de las neurociencias -en la medida en que se ocupa de identificar vínculos entre el sistema nervioso y los procesos de conducta humana, y en explorar correspondencias entre estructuras cerebrales y procesos cognitivos y emocionales- constituye, en la actualidad, un referente obligatorio en la reflexión sobre el sujeto. Como sostiene Bernal (2002):

«Es evidente que el organismo humano no se reduce al cerebro, ni tampoco la personalidad a la conciencia, pero el cerebro constituye el más complejo y diferenciado sistema orgánico del hombre, y la conciencia, que comprende toda la actividad mental superior, puede considerarse la emergencia última de la cualidad del sujeto». (Bernal, 2002, 31)

La plasticidad instaura una dimensión de apertura, un abanico de posibilidades que permite al sujeto pensar en múltiples ámbitos y niveles, en la complejidad, indeterminación e incertidumbre en la que se entreteje la construcción del sujeto y a partir de la cual es posible su reconceptualización: «La plasticidad, lejos de producir un reflejo del mundo, es la forma de otro mundo posible» (Malabou, 2004, 161). Representa, además, la posibilidad de superar la separación que ha caracterizado a la cultura occidental entre sujeto epistémico y sujeto empírico (Nunes, 2002). Esta separación se refleja en el campo cultural y educativo; por ejemplo, en la separación y a veces oposición entre humanidades y ciencias, entre ciencias naturales y ciencias humanas (Bernal, 2002).

Más allá del uso del término «plasticidad» para referirse a la naturaleza cambiante de la comunicación entre las neuronas, a la flexibilidad de las conexiones neuronales tal como existe en la literatura científica sobre el tema, el concepto «plasticidad neuronal» instaura un horizonte reflexivo que posibilita múltiples y complejos enfoques. El papel

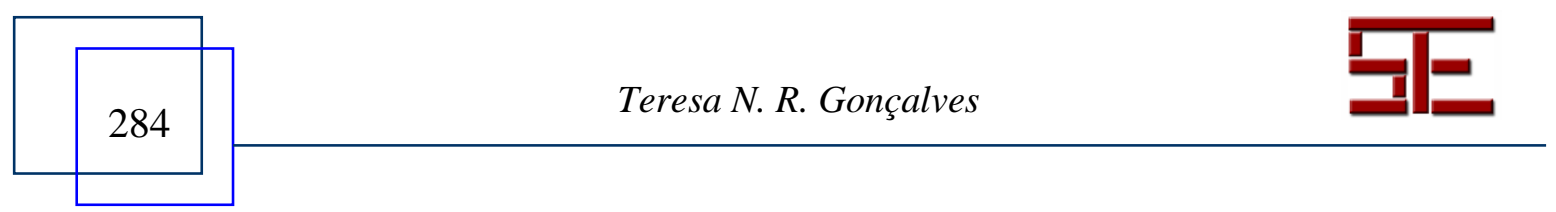




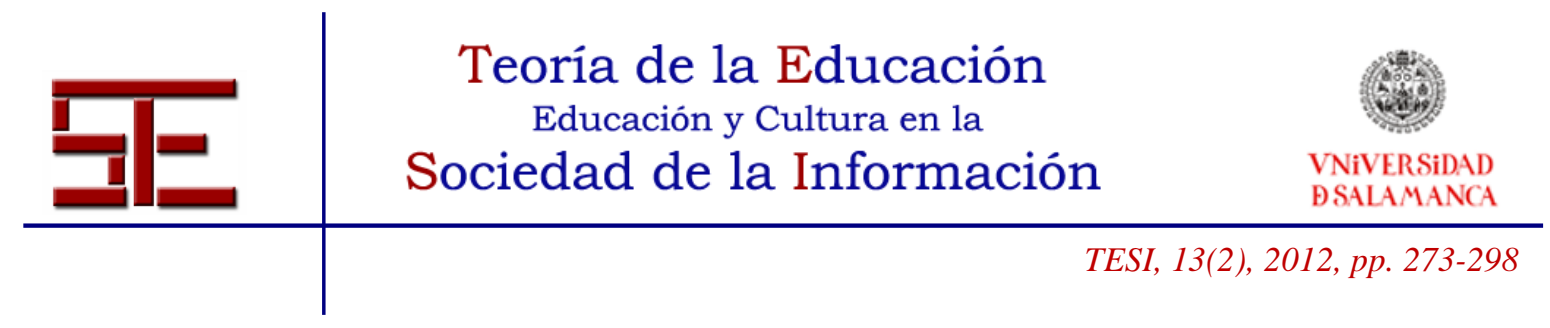

que asumen la neurogénesis ${ }^{8}$ y la sinaptogénesis ${ }^{9}$, así como la idea de apoptosis o «poda neuronal» ${ }^{10}$, contempla al sujeto como constructor de su propio cerebro, como creador de su «yo», como dador y destructor de la forma. El sujeto es escultor de sí mismo. La plasticidad representa libertad y responsabilidad, posibilita adaptación y emancipación.

Volviendo a Malabou (2004), si la conciencia y la individualidad transcienden las meras funciones o características neuronales de los sujetos, entonces, no basta con una educación centrada en esos procesos. Una perspectiva meramente neuronal aplicada a la escuela puede ser reductora si no se relaciona con otras perspectivas; es decir, si no se encuadra en esa triple dimensión de la plasticidad: estética, ética y política. En el fondo, se trata de intentar comprender cómo será posible poner los descubrimientos científicos al servicio de una comprensión educativa emancipadora. Se trata de comprender de qué manera será posible que los descubrimientos científicos aporten una comprensión educativa emancipadora (Bernal, 2011). ¿Cómo pueden los progresos de las neurociencias posibilitar la emancipación educativa del cerebro $\mathrm{y}$, con ella, la del sujeto? ¿Cómo puede la educación ayudar a los cerebros a cumplir las posibilidades contenidas en su plasticidad sin que se convierta en una justificación de la mera performatividad, de la idea de eficacia -es decir, sin que se confunda con una mera flexibilidad que apelaría a la obediencia y la docilidad-? De ahí que la del sujeto neuronal sea una cuestión fundamental.

Después del cuestionamiento de la idea moderna del sujeto que ha caracterizado al estructuralismo, la crítica moderna de la razón, de la expresividad y de la moral, así como de la pos-modernidad, pensar en el sujeto resurge como una exigencia de nuestro tiempo. La tesis moderna y, asimismo, la tesis posmoderna de la deconstrucción y fragmentación del sujeto, necesita ser repensada a partir de los nuevos conocimientos sobre el cerebro en el marco de la teoría de la complejidad. Esa exigencia se manifiesta en el ámbito de las ciencias cognitivas tanto en lo que se refiere a las ciencias humanas - como la sociología o la antropología cognitivas- como a las ciencias naturales neurociencias cognitivas o biología del conocimiento-. Parece ser que la cultura y los aspectos sociales que encuadran la existencia humana no pueden pensarse sin también pensar en un sujeto, de la misma forma que no se puede pensar en el todo orgánico que representan el organismo y el cerebro humanos sin pensar en un «yo», una consciencia que esté subyacente. Este sujeto se relaciona con los fenómenos culturales y sociales a partir de su organismo, de las posibilidades que su dimensión biológica le ofrece, desde luego. Es un sujeto que representa una realidad y que, a través de esa representación, se

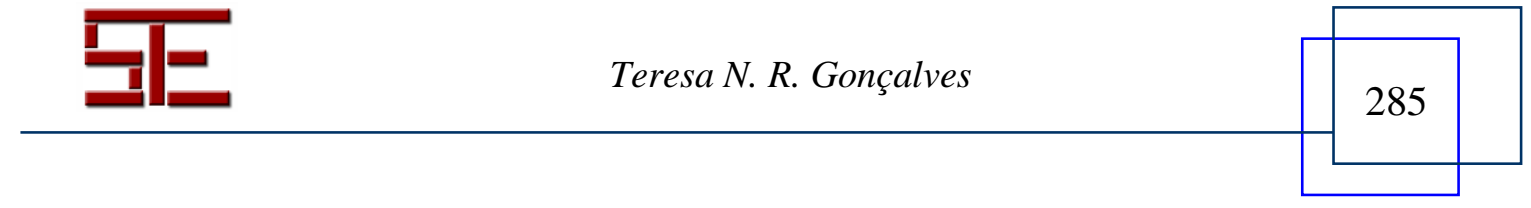




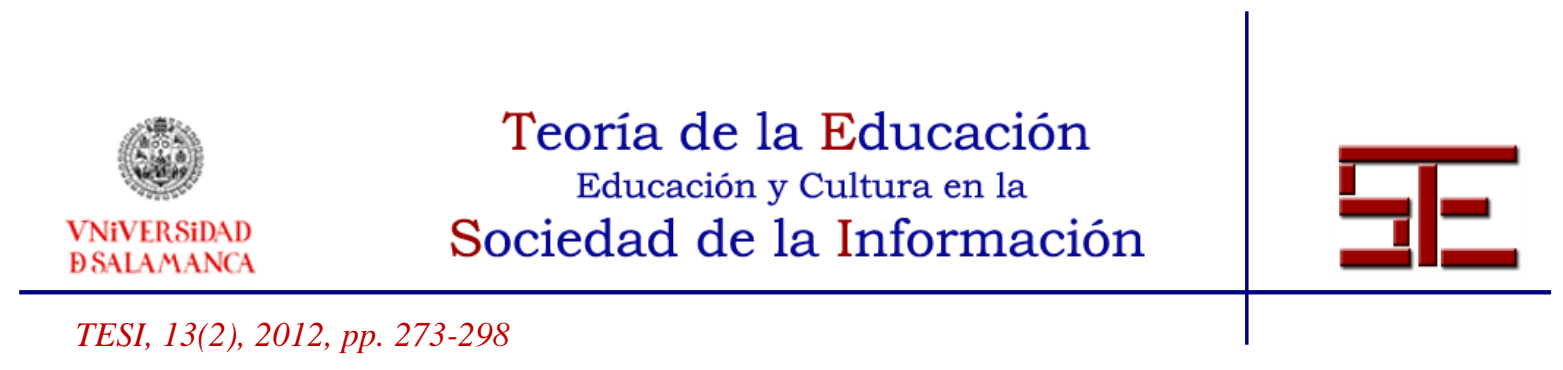

convierte en subjetividad, en individualidad. Él mismo es una realidad libre, autónoma, única e irrepetible, y además -hoy lo sabemos-, una realidad compleja, ambigua y dinámica. Es un sujeto de ambivalencias y paradojas que necesita ser pensado como tal.

\section{MULTIDIMENSIONALIDAD}

El concepto «multidimensionalidad» está relacionado con la idea de complejidad. Por sujeto multidimensional se entiende un sujeto bio-psico-social; es una construcción bioantropológica. Su identidad no es monolítica, se construye entre distintas y diferentes dimensiones interconectadas entre sí, y en las que subyace la unidad de una consciencia. Como afirma Edgar Morin (1999, 13): «Las unidades complejas, como el ser humano o la sociedad, son multidimensionales; el ser humano es, a la vez, biológico, psíquico, social, afectivo y racional», y ser complejo implica, precisamente, el funcionamiento de esas múltiples dimensiones como una unidad:

«Complexus significa lo que está tejido junto; en efecto, hay complejidad cuando son inseparables los elementos diferentes que constituyen un todo (como el económico, el político, el sociológico, el afectivo, el mitológico) y existe un tejido interdependiente, interactivo e inter-retroactivo entre el objeto de conocimiento y su contexto, las partes y el todo, el todo y las partes, las partes entre ellas. Por esto, la complejidad es la unión entre la unidad y la multiplicidad» (Morin, 1999, 14).

Considerar al sujeto en su multidimensionalidad supone tener en cuenta las distintas dimensiones en las que se procesa la construcción de su identidad. Su desarrollo resulta de la interacción entre las diversas dimensiones en las que se da, se sitúa y se configura su existencia. De acuerdo con una perspectiva sistémica compleja, la multidimensionalidad puede ser contemplada desde varios niveles:

- Relación entre biología y cultura: el hombre es un ser simultáneamente biológico y cultural o bio-psico-social. La mente está entre la relación cerebrocultura, nace de esa relación. La consciencia es una propiedad emergente del cerebro en su relación con el mundo de la cultura.

- Relación entre razón y emociones: estas funcionan tanto de forma complementaria como antagónica, pero existe una influencia mutua.

- Relación entre la dimensión individual de la existencia humana y su dimensión social y comunitaria: implica una dicotomía entre identidad y diferencia, entre lo que es común a todo ser humano y las diferencias individuales que concretizan la humanidad de cada sujeto.

Entendido desde esta perspectiva, el sujeto se presenta como bimodal (Asensio,

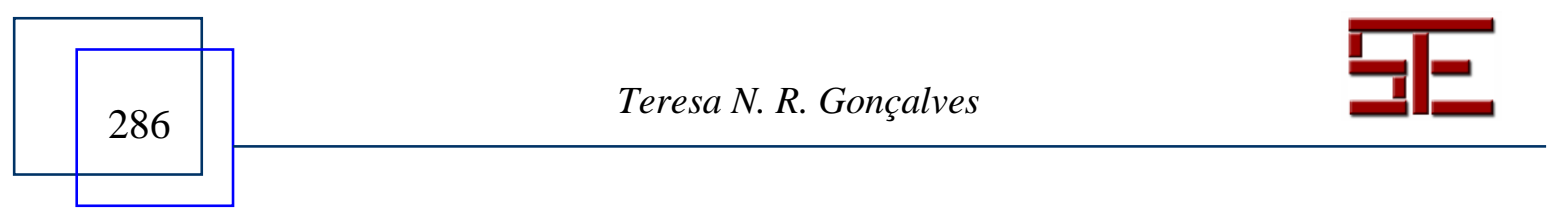




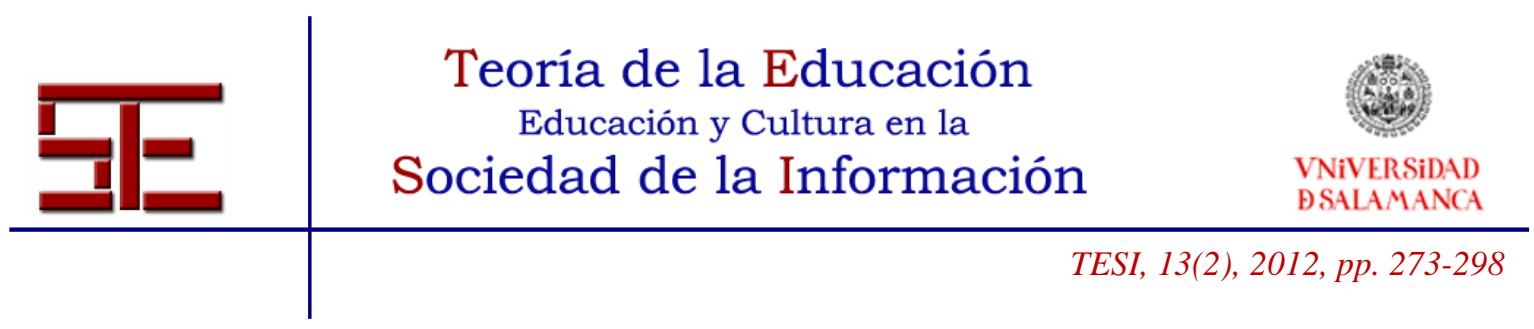

Acarín y Romero, 2006), su naturaleza y su complejidad le sitúan entre la biología y la cultura, entre la genética y el entorno, entre la razón y las emociones, entre la subjetividad y la intersubjetividad. Es, como afirma Edgar Morin (1999), Sapiens y Demens. En términos cognitivos, también se formula como multimodal (Smith, 2005) en lo que se refiere a su experiencia y relación con el mundo.

El conocimiento está conectado con el mundo a través del cuerpo. La hipótesis de la corporización (embodiment hypothesis) se refiere a la idea de que el pensamiento surge a partir de la interacción de un organismo con un ambiente, y como resultado de la actividad senso-motora (Smith, 2005). Esto sugiere que todo el conocimiento puede emerger de, estar embebido en, distribuido a través o ser inseparable de un proceso en tiempo real de percibir, recordar, esperar y actuar. De acuerdo con esta perspectiva, la cognición es un complejo conjunto de procesos internos estrechamente conectados entre sí y con el mundo mediante la percepción y la acción en tiempo real, sin representación fija o segregada de nada. En cuanto sistema complejo, la cognición no es observable ni efectiva a no ser que esté conectada con el cuerpo y al mundo físico más allá de él; en este sentido, es cognición distribuida (por el cerebro, por el cuerpo, por el mundo). La estrecha relación de la cognición con el cuerpo y con el mundo significa que no todo el conocimiento existe «en la cabeza», en mecanismos específicos, en representaciones. Puede existir en la interfaz entre el cuerpo y el mundo, y puede estar en la base del desarrollo de funciones cognitivas superiores y de la ligación de contenidos mentales separados en el tiempo (Smith, 2005). En el ámbito de la relación con el mundo y del funcionamiento de los sistemas complejos, la naturaleza de la experiencia es multimodal: «Estamos conectados al mundo físico en tiempo real a través de múltiples modalidades, mediante la vista, el oído, el tacto, el olfato, la propiocepción y el equilibrio [...]» (Smith, 2005, 290), y esta constituye la mayor fuerza de cambio en el sistema.

El sujeto de la plasticidad, no siendo una esencia ni una sustancia, tampoco es una ilusión. Como afirma Rosa Nunes $(2002,84)$, este sujeto no es «[...] ni el sujeto universal, ni el sujeto singular, ni el sujeto individual, ni el sujeto colectivo, sino lo que está entre». La categoría «sujeto» es lo que da unidad y coherencia a una pluralidad de personajes, de características, de potencialidades, de dimensiones. La identidad misma ya no se define como un proceso de autoconstitución en el seno del cual el sujeto lidiaría con una serie de posibles configuraciones de sí mismo. Todo el sujeto vive

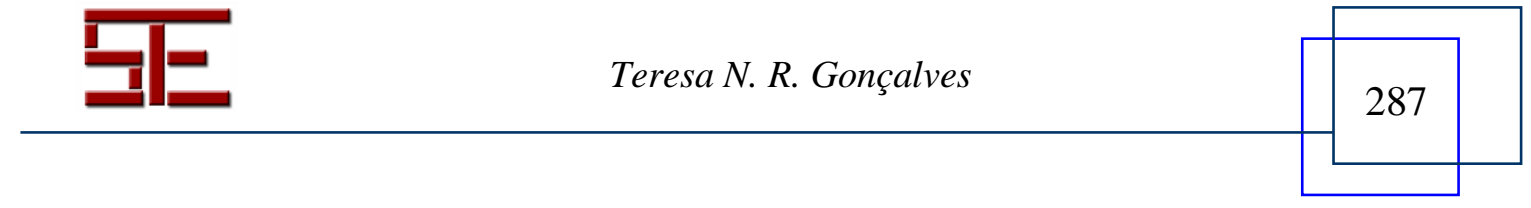




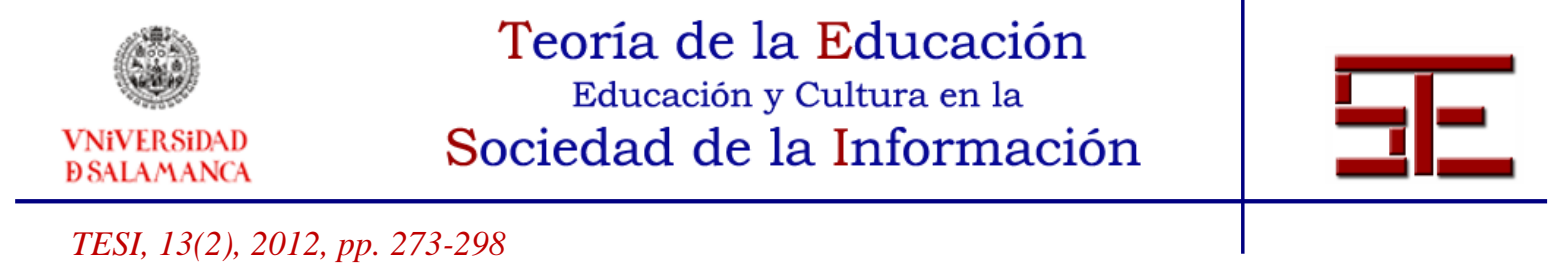

múltiples vidas, al mismo tiempo y sucesivamente (Malabou, 2004). Por eso, toda identidad es problemática, contradictoria y conflictiva (Bernal y Gonçalves, 2006).

El sujeto es multidimensional, es el resultado de la resiliencia ${ }^{11}$, es una realidad compleja que incluye un sujeto natural, un sujeto de representación y un sujeto corporeizado (Martínez-Freire, 2001). Incluye procesos mentales (sensaciones, percepciones, recuerdos, creencias, inferencias, voliciones y sentimientos), los suyos y los de los demás con los que se relaciona; es, en fin, un sujeto comunicacional. Esa dimensión es condición de posibilidad de su propia individualidad, de la construcción de su subjetividad.

Nuestra naturaleza multimodal guía el cambio desenvolvimental auto-organizado y sustenta el sustrato social del desarrollo cognitivo. El desarrollo en un mundo social proporciona, además de la posibilidad de aprender de otros mejor preparados, un nivel adicional y correlaciones multimodales de orden superior cruciales para el concepto de «yo», «otro», «intención» y la llamada «teoría de la mente» (Leslie, Fridman y German, 2004). El sujeto es un cuerpo con un sistema cognitivo en el mundo, conjuntamente con otros cuerpos y sistemas cognitivos con los cuales establece interrelaciones y a los cuales ajusta su comportamiento. Esas relaciones, estos entre, configuran el desarrollo del sujeto y ocurren en un tiempo y en un contexto concretos. Por eso, los conceptos que explican esas relaciones deben ser complejos y contextualizados. La cognición emerge en el tiempo, es el producto emergente de muchos sistemas heterogéneos acoplados entre sí y al mundo en tiempo real (Smith, 2005).

\section{NARRATIVIDAD}

Si, como afirma Mario Bunge $(2004,245)$, entendemos el cerebro como un sistema cuya estructura es integral, la mente es unitaria.

«Nos sentimos como unidades, antes que como un mosaico de memoria, emoción, cognición, volición, etc., porque el yo es unitario. Esto no equivale a decir que hay una única función mental, y mucho menos que la mente y el cerebro son similares. La tesis defendida aquí es que los módulos cerebrales no funcionan independientemente unos de otros, ninguno de ellos funciona de forma aislada de los restantes».

Entendida en este sentido, la persona es un sistema dotado de una conciencia y en continua interacción con el medio y con los demás.

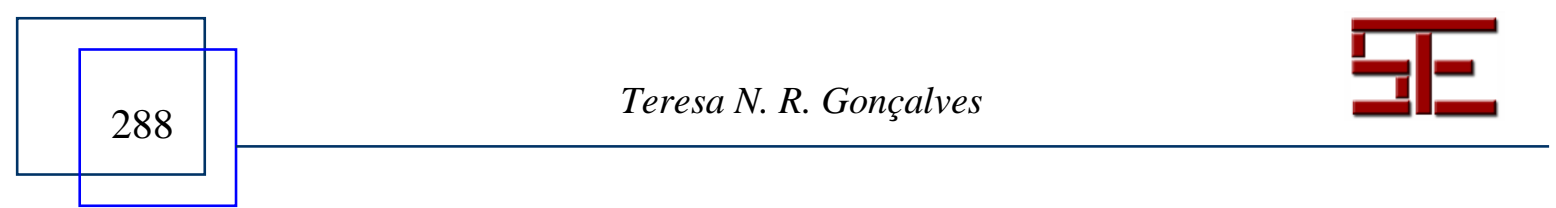




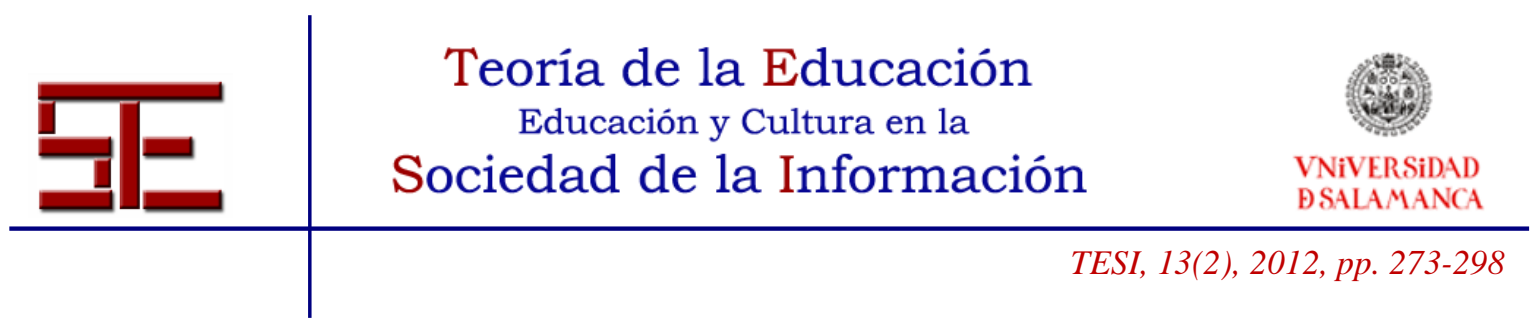

En el marco de la complejidad y de las múltiples tensiones que constituyen la vida del sujeto, el concepto «atractor» ${ }^{12}$ refleja la interrelación entre estructura y dinámica, y encuadra la tensión entre estabilidad y cambio en lo que se refiere a los procesos psicológicos. Resulta de la comunicación recíproca entre cognición y emoción que, progresivamente, va dando lugar a la formación de atractores estables. Conceptualizar la personalidad en términos de dinámica de los atractores permite comprender la tendencia humana tanto para el cambio continuo como para crear y mantener la estabilidad personal en la interacción con el entorno. El desarrollo de atractores restringe la variación intra-individual y la aparición de diferencias inter-individuales (Nowak, Vallacher y Zochowsky, 2005).

Sin embargo, los atractores no tienen necesariamente que ver con intenciones o estados deseados, en la medida en la que pueden converger hacia estados violentos, depresivos $\mathrm{u}$ otros. El concepto de atractor representa una tendencia para un determinado estado, pero se define mediante la trayectoria vital de los sujetos y existe dentro de un sistema con múltiples y distintos atractores, lo que explica que los sujetos puedan tener objetivos, autoconceptos, patrones de comportamiento diferentes y conflictivos (contrarios) que deben, sin embargo, ser modulados por la autorregulación. De ahí el papel de las emociones y la importancia de la relación entre cognición y emociones en la definición de los atractores. El envolvimiento entre estas tendencias contradictorias y la capacidad de autorregulación están en la base de la capacidad narrativa de los sujetos, la cual posibilita la atribución de significados y la coherencia comportamental. El «yo» funciona como una importante plataforma de regulación del pensamiento, de la emoción y de la acción, así como de las relaciones interpersonales (relación con la formación del auto-concepto).

La capacidad narrativa unifica las diferentes dimensiones del sujeto en una historia de desarrollo. La narratividad es la categoría que introduce una dimensión temporal en la comprensión del sujeto y está relacionada con el lenguaje, la memoria, la emoción y la producción de sentido. La estructura narrativa es lo que otorga sentido a la realidad y a la historia personal; en definitiva, a la vida misma. Se construye entre la memoria y el olvido, por eso es necesario no solo aprender a recordar, sino también a olvidar (a borrar el recuerdo). La idea del sujeto como escultor de sí mismo, de su propio cerebro, se constituye como una metáfora de la narratividad. Esta metáfora está relacionada con la plasticidad, y el proceso de construcción de la identidad, a su vez, se relaciona con el trabajo del escultor que da forma a su propia vida, que esculpe su identidad, cuenta

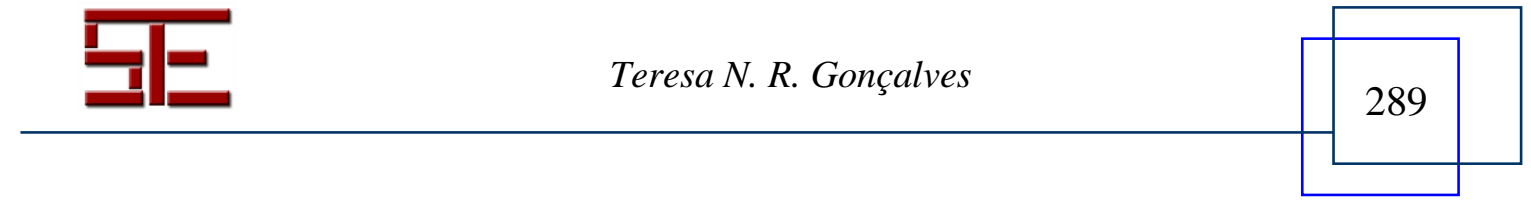




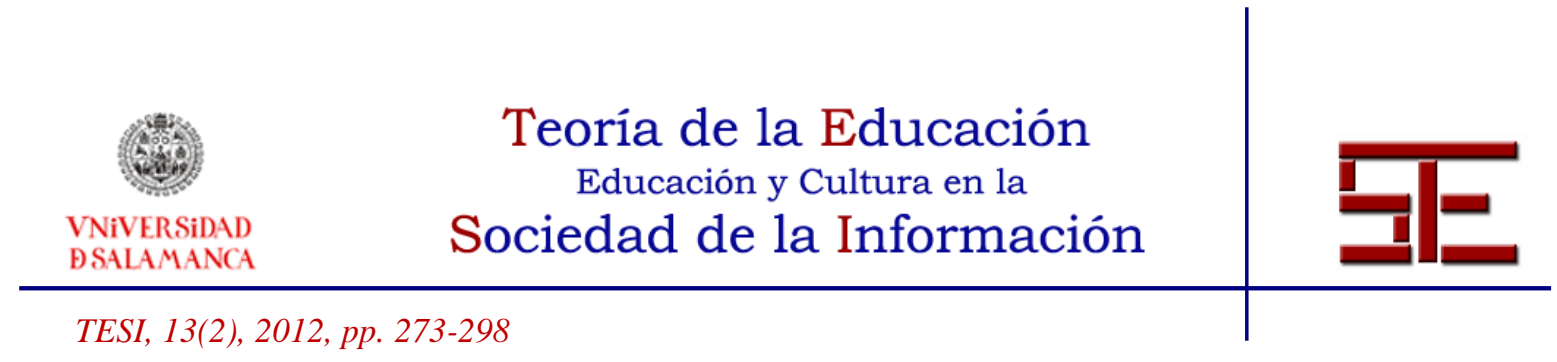

historias para atribuir significado a la realidad y dar sentido a su existencia, incorporando conceptos y construyendo representaciones.

La narratividad añade a los atractores el hecho de ser un proceso consciente y simbólico, mientras que la formación de los atractores puede no serlo. La narrativa personal se compone de elementos cognitivos que representan la auto-información relevante y de mecanismos que dan coherencia y estabilidad a la comprensión de uno mismo. De la misma forma, estos mecanismos están en la base del consenso y de la identificación social, a pesar de que esa comprensión sea compleja y, a veces, conflictiva y oscilante (Nowak, Vallacher y Zochowsky, 2005).

La identidad es narrativa en la medida en que constituye un proceso interpretativo de las experiencias cognitivas, emocionales, perceptivas y afectivas que marcan la historia vital de los individuos y que configuran su memoria y, por tanto, su existencia. El sujeto se rescribe continuamente y simultáneamente en distintos tiempos y dimensiones. Las continuas modificaciones de la mente humana ocurren en un horizonte de sentido que posibilita la acción coherente, la conducta sabia, la prudencia y la responsabilidad (Asensio, 1997). La narratividad sitúa la experiencia vital frente a la temporalidad pasada, presente y futura, pero no obedece a una lógica lineal y sistematizada, sino a una discontinuidad permanente que implica rupturas y transiciones en las que se va tejiendo la trama del sentido vital. Por eso, la identidad narrativa no existe al margen de la dimensión material y práctica ni de las condiciones y relaciones objetivas que marcan la vida de los individuos; por eso, todas las identidades son problemáticas, conflictivas, múltiples y dinámicas, y «se sitúan entre lo ideal y lo real, entre lo que no hemos llegado a ser y lo que somos» (Bernal y Gonçalves, 2006, 160).

«Atender a la modalidad narrativa implica un cambio del lenguaje de la pedagogía preferiblemente hacia las interpretaciones plausibles antes que a las explicaciones causales [...] nuestra capacidad de narración cumple su mejor función cuando es capaz de imaginar otros «yos» posibles, otros mundos posibles» (Bernal, 2005, 125).

En cuanto apertura de posibilidades, la plasticidad es la condición de posibilidad misma de la narratividad de la existencia humana. Instaura un horizonte de libertad posible del sujeto y, con él, también la diferencia como condición básica para la narratividad. Así entendida, la diferencia no es un mero accidente, es la base misma desde la que se puede pensar la existencia humana y, consecuentemente, reflexionar sobre la formación de los seres humanos (García Carrasco, 2007). Como ha demostrado Damásio (1994, 2001), la capacidad narrativa está estrechamente relacionada con la dimensión emocional del ser

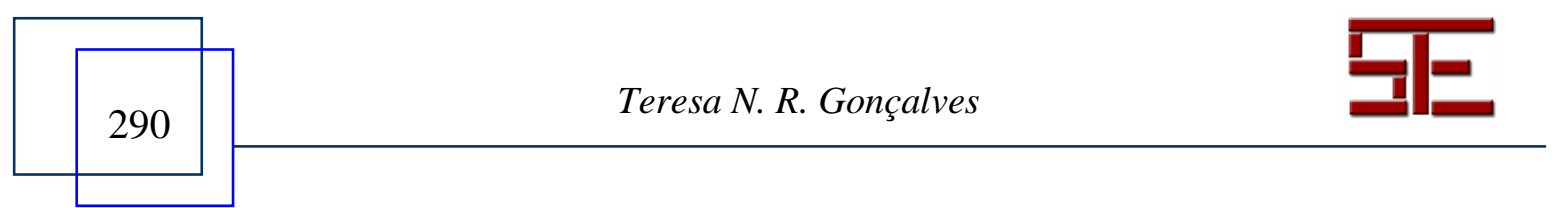




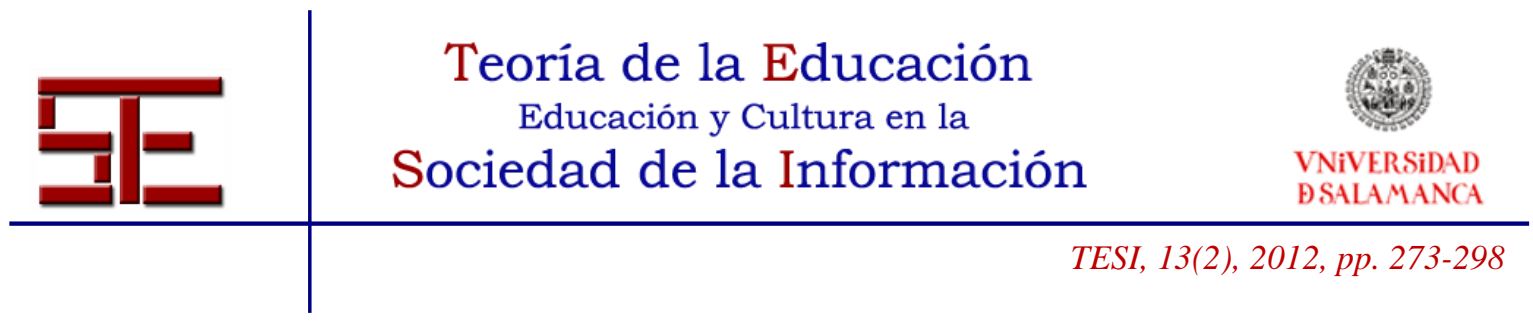

humano y con la relación entre cognición y emociones en lo que respecta a la toma de decisiones.

Hablar en narratividad implica añadir su dimensión emocional y social al discurso sobre las capacidades humanas, relacionar la «inteligencia paradigmática» (Bruner, 1988) con la «inteligencia social» o, en palabras de Maturana (2003), la «inteligencia compartida», que encuadra las prácticas humanas y se construye a partir de su intencionalidad. El lenguaje (o lenguajes) humano es el principal instrumento de construcción de la identidad narrativa, dado que abre el sujeto al sentido, a los significados, a la comunicación, a la expresión, a compartir. La relevancia de los relatos en los procesos de construcción de la identidad, ya sea individual, social o cultural, fundamenta la importancia que se les debe atribuir en las prácticas educativas. La literatura, las artes plásticas, la música y todas las otras formas y vehículos de expresión humana representan importantes instrumentos de construcción de la identidad.

\section{LA POSIBILIDAD COMO PROPUESTA PEDAGÓGICA}

El sujeto es un sistema integrado, dinámico, y no cerrado. No se encuentra ni determinado ni indeterminado, en absoluto. Su desarrollo acontece entre una predeterminación genética que define las reglas e impone límites, pero que no es determinismo -está abierto a la indeterminación, a la posibilidad-, y unos condicionalismos contextuales y ambientales que también, y simultáneamente, definen límites y ofrecen posibilidades. El sujeto emerge entre estas dos dimensiones. La historia del desarrollo será lo que determinará qué posibilidades se van a realizar y cuáles se quedarán por cumplir. La intencionalidad del sujeto será lo que marcará el espacio posible, que es, todavía, un inmenso espacio de libertad en el que se construye su identidad.

En el campo educativo, no solamente es necesario este devenir sujeto y la definición del espacio que ocupa la idea de sujeto en la educación, sino también reflexionar sobre la forma en la que la educación puede ayudar al sujeto en la comprensión de su propia transformación; es decir, cómo pueden ser realizadas para el sujeto las promesas del nuevo orden neuronal. En esta tarea no bastan las ciencias cognitivas, se necesita también crear un espacio político, filosófico o cultural en el que las promesas de la plasticidad puedan ser pensadas y desarrolladas en los ámbitos teórico y práctico. De lo que se trata es de cuestionar cómo esas promesas pueden hacer a los individuos más

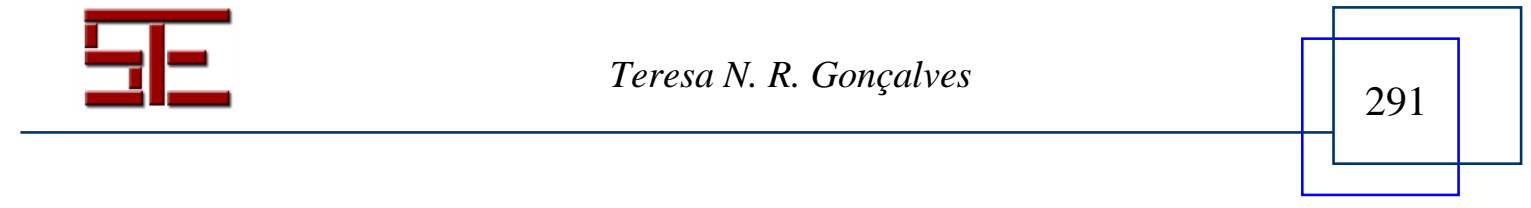




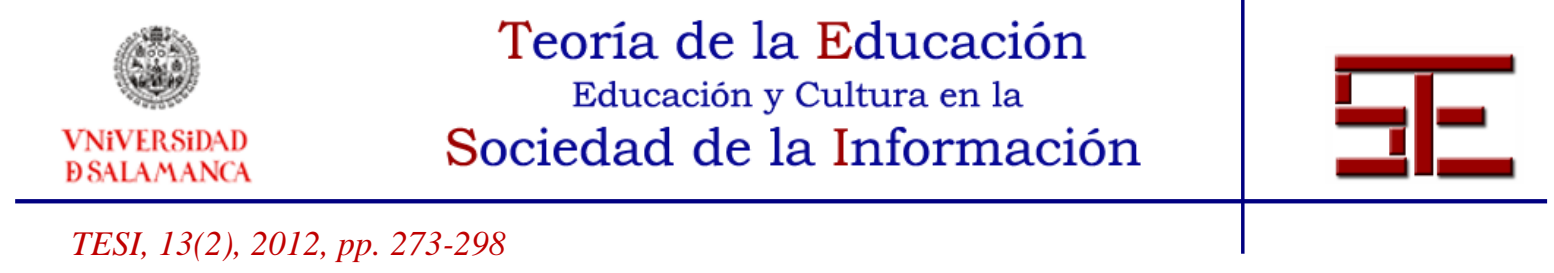

libres, más inteligentes y más felices; en fin, resistir a la ideología de la flexibilidad (Malabou, 2004).

Será también necesario deconstruir, adoptando una actitud posmoderna (Bernal, 2011), tanto los discursos educativos y pedagógicos como los económicos, políticos y científicos centrados en la idea de acción y eficacia, discursos que constriñen al sujeto en una lógica de manutención, de imitación, de obediencia. Discursos normativos y normalizadores que destruyen toda curiosidad, toda creatividad y voluntad de un sujeto, cuya existencia consiste nada más que en formar parte de una serie de sistemas de manutención de un dispositivo político, económico y social que constantemente remite a la flexibilidad y la utilidad, y no a una plasticidad liberadora.

Bernal (2011) se refiere al discurso normalizador y evaluador que emana de las políticas educativas contemporáneas y que, en nombre de la promoción de la calidad de los sistemas educativos, genera una vorágine evaluadora centrada en los estándares y en el rendimiento de cuentas, y que puede poner en peligro la tarea misma de educar.

«Obsesionados por las pruebas, profesores y estudiantes pueden privarse de la mejor enseñanza y del mejor aprendizaje» (Darling-Hammond, 2001). La crítica posmoderna ha puesto sobradamente de relieve el peligro de que la 'performatividad ' y el 'saber cómo ' (know how) representen los valores supremos del saber. Es preciso repensar la educación situándola en contextos de significado plenamente humano». (Bernal, 291-292).

Stoer y Magalhães (2002) refieren las implicaciones de la contaminación del discurso y práctica educativos por las instancias productivas. Estas, más allá de la indefinición de sus fronteras, asumen una cándida funcionalidad. Según los autores, el conocimiento, cuando contextualizado como competencia y performatividad, deja de estar al servicio de la formación del individuo como tal para convertirse en algo que fluye a través de él, dotándole de capacidades de respuesta a situaciones más o menos restringidas y más o menos complejas, pero no interfiriendo en su formación en cuanto tal. Por eso, formar para la competencia y para la flexibilidad no significa necesariamente formar para la plasticidad y para la libertad.

La cuestión central en educación no será sobre la posibilidad de activar las regiones cerebrales apropiadas para mejorar sus aptitudes, pero sí pensar cómo puede contribuir la educación para cumplir, en la práctica, las promesas de la plasticidad cerebral y de la referida revolución neuronal, forneciendo al sujeto con instrumentos para comprender y emprender su propia trasformación. Es necesario un discurso anclado en la vida misma,

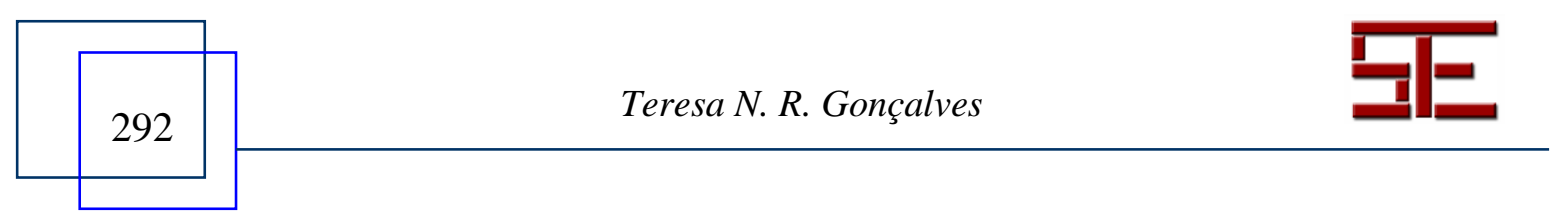




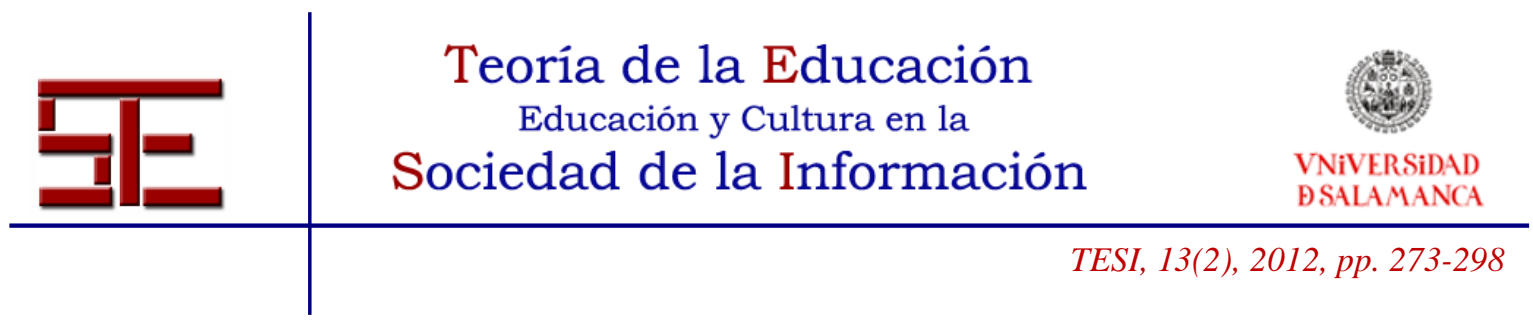

en la dinámica de liberación neuronal del sujeto de la plasticidad, un discurso centrado en la realización y ampliación de nuestras posibilidades.

Importa, por eso, que la pedagogía del sujeto sea, ante todo, una pedagogía de la posibilidad, una pedagogía de la transformación formadora que refleje, como refiere Damásio, la actividad poética que se produce en nuestro cerebro. La pedagogía de la posibilidad se integra en el paradigma de la complejidad, se encuadra en la perspectiva del sujeto como sistema abierto y autónomo, emergente y auto-organizado. La pedagogía del sujeto se sitúa en el marco de una política del sujeto, de una ética del sujeto y de una estética del sujeto, que serán una política, una ética y una estética de la plasticidad. Se trata del entre al que se refería Rosa Nunes (2002) y que Malabou (2004) denomina entre-deux, situándolo en la tensión dialéctica que une y opone simultáneamente naturalidad e intencionalidad, el centro vivo de una realidad compleja.

La idea de una pedagogía de la posibilidad, entendida en el marco de la complejidad y de la plasticidad, dirige la acción educativa no hacia la causalidad, sino hacia la posibilidad. La posibilidad se entiende no como potencialidad -lo que todavía correspondería a una lógica lineal y causal-, sino como lo que aún no es imaginable (not-yet-imaginable), concepto propuesto por Davis y Sumara (2007). En términos de Larrosa (1999), se trata de cuestionar lo obvio y ampliar lo posible más allá de lo ya previsto, lo ya pensado, lo ya leído y lo ya dicho. Implica también una continua negociación de sentido entre el sujeto y el mundo. Considerada de esta forma, la educación se encuadra en una epistemología de la emergencia (Osberg, Biesta y Cilliers, 2008), una epistemología de la temporalidad y de la imprevisibilidad. La apertura a la emergencia, la creación de oportunidades para que la emergencia ocurra, encoraja al aprendizaje y es la clave de una educación entendida en el marco de la complejidad. El aprendizaje es «un proceso de emergencia y coevolución del individuo, del grupo social y de la sociedad en general» (Mason, 2008, 25). El sujeto es agente de su emergencia en cuanto sujeto, de su devenir en los múltiples contextos en los que se da su formación y con los múltiples otros sujetos con los que se relaciona. La idea de teaching as occasioning (enseñar como ocasionar, suscitar - crear la oportunidad), expresada por Davis (2004) en relación con las perspectivas sobre la enseñanza emergentes de la teoría de la complejidad, refleja este entendimiento de una pedagogía de la posibilidad en la que el papel del profesor es crear oportunidades para que la emergencia ocurra en la multidimensionalidad y complejidad ecológica del aula, teniendo en cuenta la naturaleza plástica de los cerebros de los sujetos que la componen. La idea de experiencia, con el sentido que le atribuye Larrosa (2002), asume su posición central en

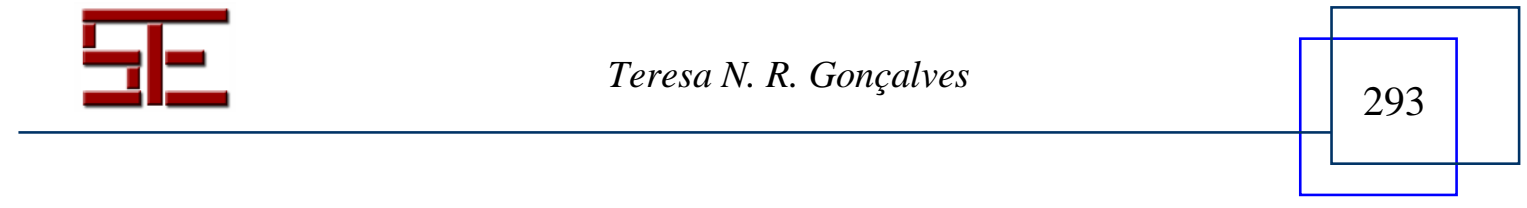




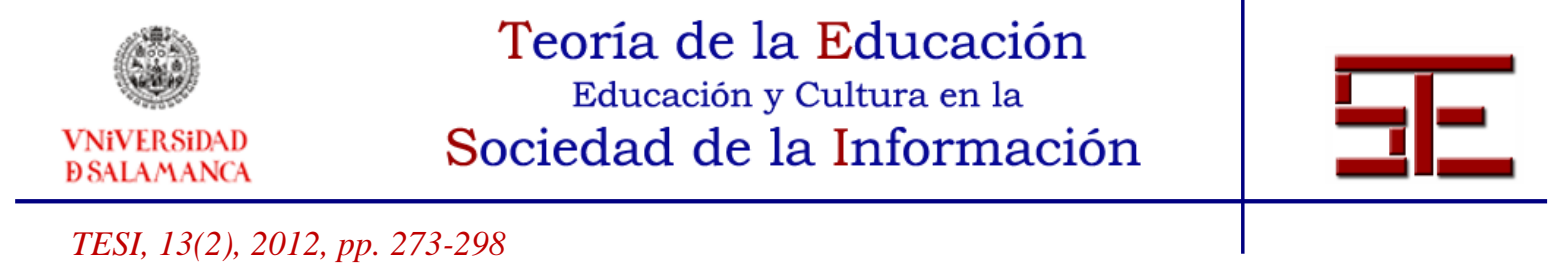

la educación. La identidad es narrativa porque se inscribe en la vida misma, resulta de la referida continua negociación de sentido entre sujeto y mundo. Sujeto y mundo forman parte del mismo sistema complejo. El sujeto de la plasticidad es un sujeto de la temporalidad, de la no-linealidad, del devenir. Un entendimiento complejo del sujeto y de la educación reconoce las posibilidades educadoras existentes en el aula y más allá de sus fronteras y límites, y dirige su acción hacia destinos desconocidos.

\section{BIBLIOGRAFÍA.}

Asensio, J. M. (1997). Biología y Educación: el ser educable. Barcelona: Ariel.

Asensio, J. M.; Acarín, N.; Romero, C. (2006). Emociones, desarrollo humano y relaciones educativas. En J. M. Asensio, J. García Carrasco, L. Núñez Cubero \& J. Larrosa (Coords.) (2006). La Vida Emocional: Las emociones y la formación de la identidad humana, (pp. 22-68). Barcelona: Ariel.

Asensio, J. M.; García Carrasco, J.; Núñez Cubero, L.; Larrosa, J. (Coords.) (2006). La Vida Emocional: Las emociones y la formación de la identidad humana. Barcelona: Ariel.

Bernal, A. (2002). Reconceptualización de la idea de sujeto y educación. En A. Bernal (Coord.), Persona, Currículum y Postmodernidad, (pp. 25-62). Barcelona, PPU.

- (2011). Postmodernización y educación. Notas para el debate de una narrativa pedagógica centrada en la identidad. Educación XX1, 14 (2), 2011, 285-302.

Bernal, A. \& Gonçalves, T. (2006). Nuevo enfoque pedagógico a partir de la plasticidad y de la narratividad. Bordón, 58 (2), 155-167.

Bunge, M. (1989). Mente y Sociedad. Ensayos Irritantes. Madrid: Alianza.

- (2004). Emergencia y Convergencia: Novedad Cualitativa y Unidad del Conocimiento. Barcelona: Gedisa.

Bruner, J. (1988). Realidad Mental y Mundos Posibles. Los actos de la imaginación que dan sentido a la experiencia. Barcelona: Gedisa.

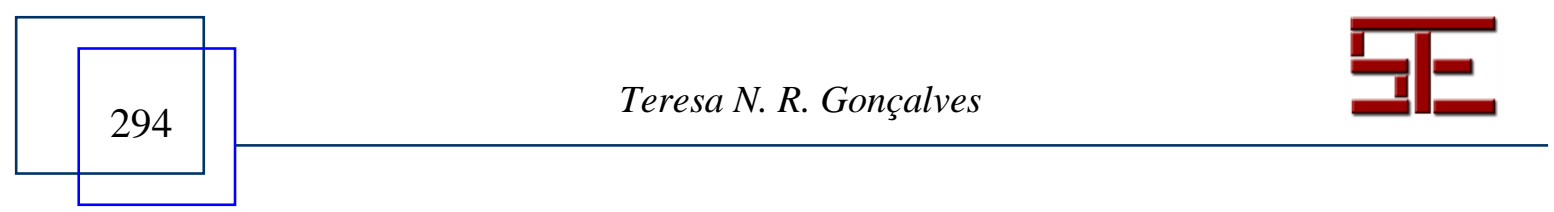




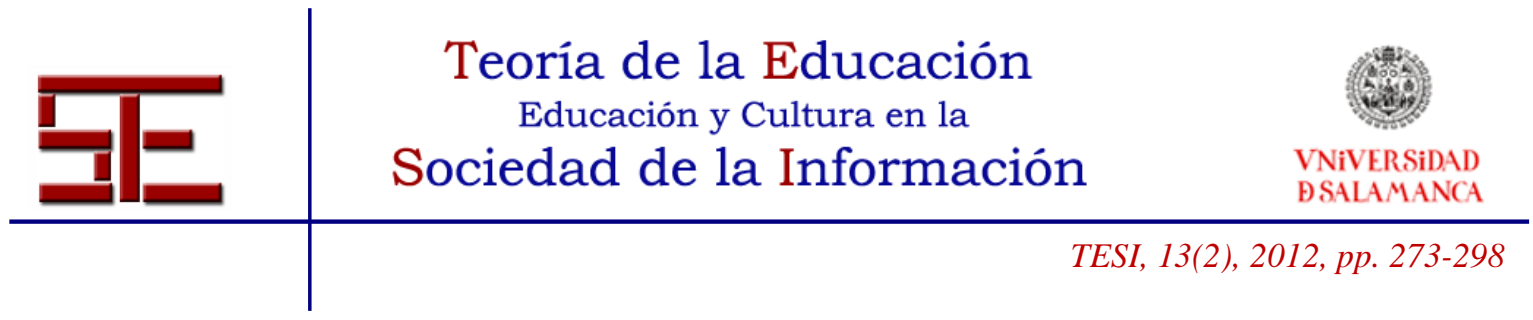

Damásio, A. (1994). Descartes' Error: Emotion, Reason and the Human Brain. London: Picador.

- (2001). O Sentimento de Si: O Corpo, a Emoção e a Neurobiologia da Consciência. Mem Martins: Publicações Europa-América.

Davis, B. (2004). Davis, B. (2004). Inventions of teaching. A genealogy. New York, London: Lawrence Erlbaum Associates.

Davis, B. \& Sumara D. (2007). Complexity science and education: Reconceptualizing the teacher's role in learning. Interchange: A Quarterly Review of Education, 38 (1), 5367.

Frith, U. \& Blackmore, S. (2007). Cómo aprende el cerebro. Las claves para la educación. Barcelona: Ariel.

García Carrasco, J. (2007). Leer en la Cara y en el Mundo. Barcelona: Herder Editorial.

Goldberg, E. (2006). La paradoja de la sabiduría. Barcelona: Crítica.

Gonçalves, T. (2009). Plastic brains and complex systems: a trans-disciplinary approach to education and cognitive sciences. En Karanika-Murray \& Wisemens (Eds.), Exploring avenues to interdisciplinary research: from cross to multi to interdisciplinarity. Nottingham: Nottingham University Press.

- (2010). Promoção de habilidades cognitivas e educação: um modelo de análise de programas de desenvolvimento cognitivo. Revista Brasileira de Educação, 15 (45), 564-579.

Leslie, A. M., Friedman, O. \& German, T. P. (2004). Core mechanisms in 'theory of mind'. Trends in Cognitive Sciences, 8 (12), 529-533.

Lewis, M. D. (2005). Self- organizing individual differences in brain development. Developmental Review, 25, 252-277.

Lewontin, R. (1998). A Tripla Hélice. Gene, Organismo, Ambiente. Lisboa: Edições 70.

Magalhães, A. \& Stoer, S. (2002). A nova classe média e a reconfiguração do mandato endereçado ao sistema educativo. Educação, Sociedade e Culturas, 18, 25-40.

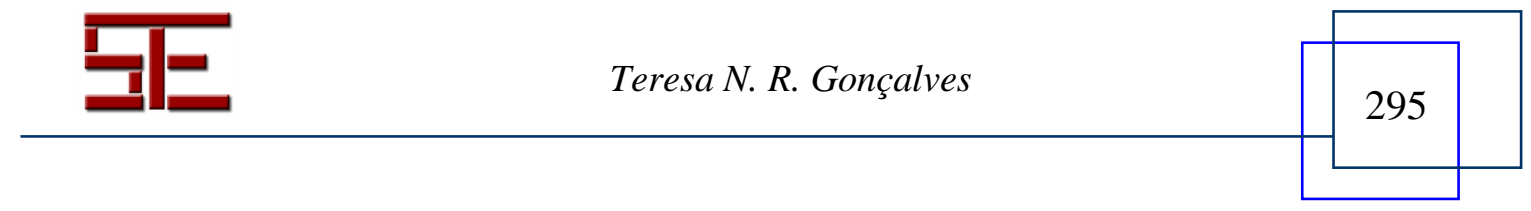




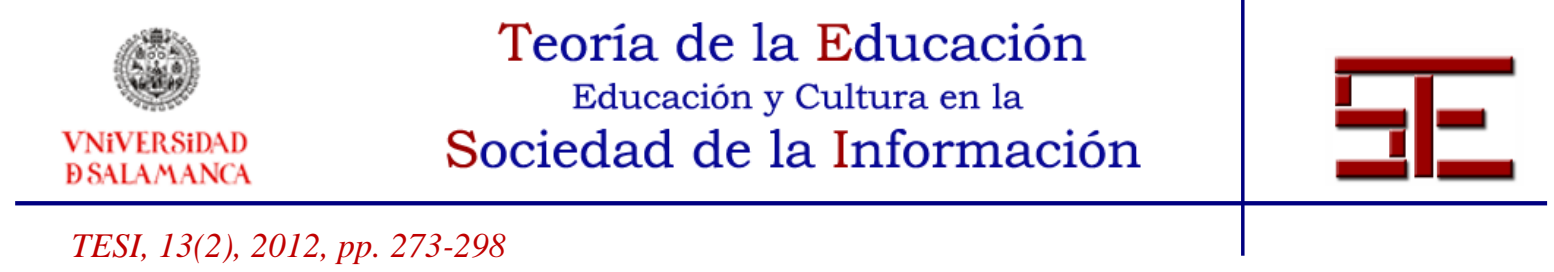

Malabou, C. (2004). Que Faire de Notre Cerveau? Paris: Bayard.

Martínez-Freire, P. (2001). La realidad desde la mente. Contrastes: Revista Interdisciplinar de Filosofía, 6, 189-213.

Mason, M. B. (Ed.) (2008). Complexity Theory and the Philosophy of Education. Oxford, UK: Wiley-Blackwell.

Maturana, H.; López, M.; Pérez, A.; Santos, M. (2003). Conversando con Maturana de Educación. Málaga: Ediciones Aljibe.

Morin, E. (1999). Los Siete Saberes Necesarios a la Educación del Futuro. Paris: UNESCO.

Moya, C. J. (2001). Emociones, racionalidad y responsabilidad. Contrastes: Revista Interdisciplinar de Filosofía, 6, 241-256.

Nowak, A.; Vallacher, R. ; Zochowski, M. (2005). The emergence of personality: dynamic foundations of individual variation. Developmental Review, 25, 351-385.

Nunes, R. (2002). E a escola? Educação, Sociedade \& Culturas, 18, 67-86.

OCDE (2002). Understanding the Brain. Towards a New Learning Science. Paris: OCDE.

- (2007). Understanding the Brain. The Birth of a Learning Science. Paris: OCDE.

- (2010). The nature of learning. Using research to inspire practice. Paris: OCDE.

Osberg, D.; Biesta, G. \& Cilliers, P. (2008). From representation to emergence: Complexity's challenge to the epistemology of schooling. Educational Philosophy and Theory 40, (1), 213-27.

Riviére, A. (1987). El sujeto de la Psicología Cognitiva. Madrid: Alianza.

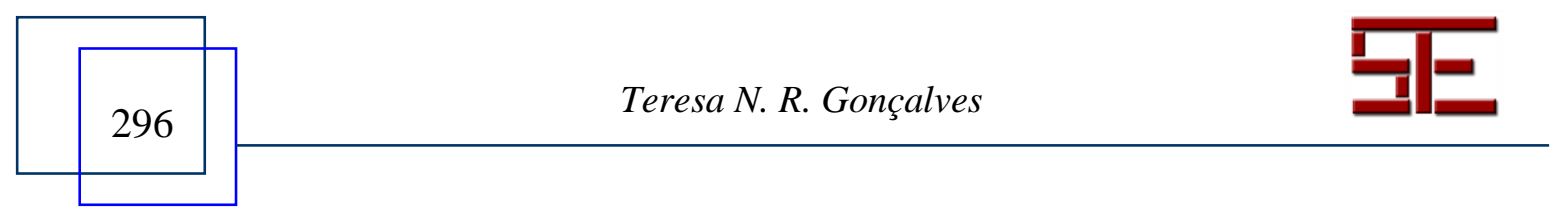




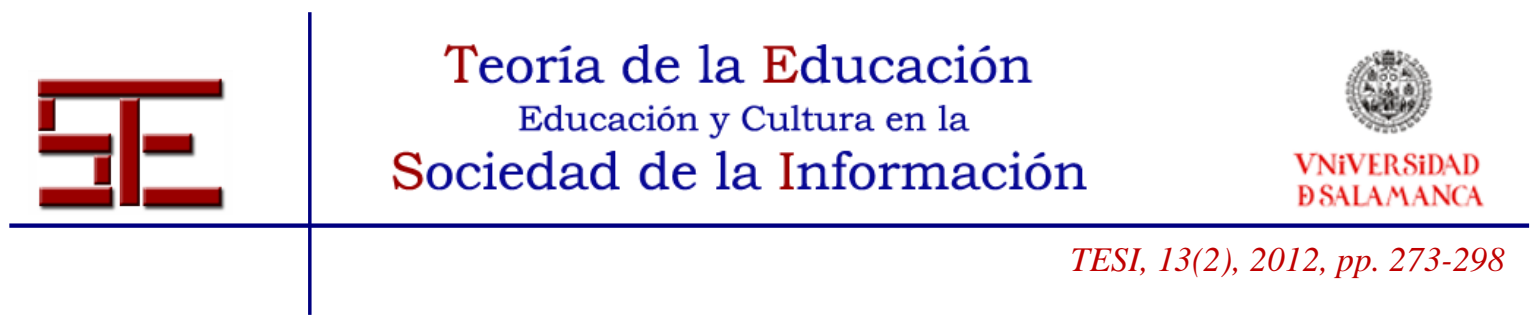

\section{Roldán Castro, I. (1999). Caos y comunicación: la teoría del caos y la comunicación humana. Sevilla: Mergablum.}

Smith, L. B. (2005). Cognition as a dynamic system: Principles from embodiment. Developmental Review, 25, 278-298.

\section{NOTAS:}

${ }^{1}$ En el cerebro, la plasticidad se manifiesta como neuroplasticidad, y representa la capacidad que tiene el cerebro para configurarse y reconfigurarse a lo largo de la vida. Las redes neuronales se organizan y reorganizan de acuerdo con las experiencias de los individuos, y se pueden modificar a lo largo de toda su vida (Gonçalves 2010).

${ }^{2}$ El concepto «ventanas de oportunidad» ilustra esta idea: existen períodos sensibles en los que la experiencia determina el desarrollo del cerebro. En esos períodos, el cerebro se encuentra más disponible y receptivo a determinado tipo de experiencias (Frith y Blackmore, 2007).

${ }^{3}$ La plasticidad experiencia- expectante se corresponde con la modificación estructural del cerebro en la infancia de acuerdo con su predisposición genética. Está ligada a la condición natural de un cerebro sano que permitiría el aprendizaje continuo hasta una edad avanzada (OCDE, 2007). Este concepto está relacionado con las «ventanas de oportunidad».

4 La plasticidad experiencia-dependiente se corresponde con la modificación estructural del cerebro como resultado de su exposición a ambientes complejos a lo largo de la vida (OCDE, 2007).

${ }^{5}$ El nuevo entendimiento del sujeto en el marco de la plasticidad y de la complejidad tiene importantes implicaciones epistemológicas. Nuevos paradigmas de investigación y nuevas formas de colaboración que sobrepasen las barreras entre las disciplinas se hacen necesarios. Se considera que la relación entre ciencias cognitivas y ciencias de la educación tiene una naturaleza transdiciplinaria. Se entiende la «transdisciplinaridad» como unificación a través de la fusión, no de la reducción (Bunge, 2004), de diferentes procedimientos, métodos y datos científicos, lo que también implica nuevas metodologías y nuevas instituciones (Gonçalves, 2009).

${ }^{6}$ Mario Bunge (1989, 21) afirma: «Todo proceso mental es un proceso específico en (peculiar de) algún sistema neuronal plástico; o sea, de conectividad variable».

${ }_{7}^{7}$ Mario Bunge (2004) afirma que la necesaria convergencia de diferentes disciplinas para explicar realidades y acontecimientos polifacéticos y multinivel requiere la aparición de nuevos conceptos y de hipótesis puente o «pegamento». Los conceptos de plasticidad y educabilidad son conceptos-puente en la medida en que son interdependientes, hacen la ligación entre dos niveles: el neurológico y el educativo.

${ }^{8}$ Aumento del número de conexiones neuronales.

${ }^{9}$ Aumento del número de conexiones sinápticas.

${ }^{10}$ La apoptosis o muerte celular programada es un tipo de «autodestrucción celular» que tiene una función homeostática, de regulación fisiológica. La «poda neuronal» acontece a lo largo del proceso de desarrollo del cerebro, y los neuronios excedentes son progesivamente eliminados para mantener el equilíbrio y optimizar el funcionamiento del cerebro.

${ }^{11}$ La resiliencia es la capacidad que tiene el cerebro para sobrepasar obstáculos, superar traumas, sobrevivir y reconstruirse en la adversidad. Es una cualidad física que subyace y soporta a la plasticidad.

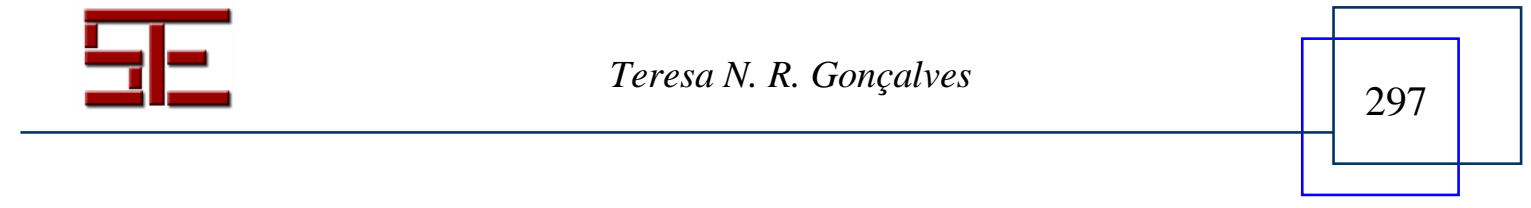




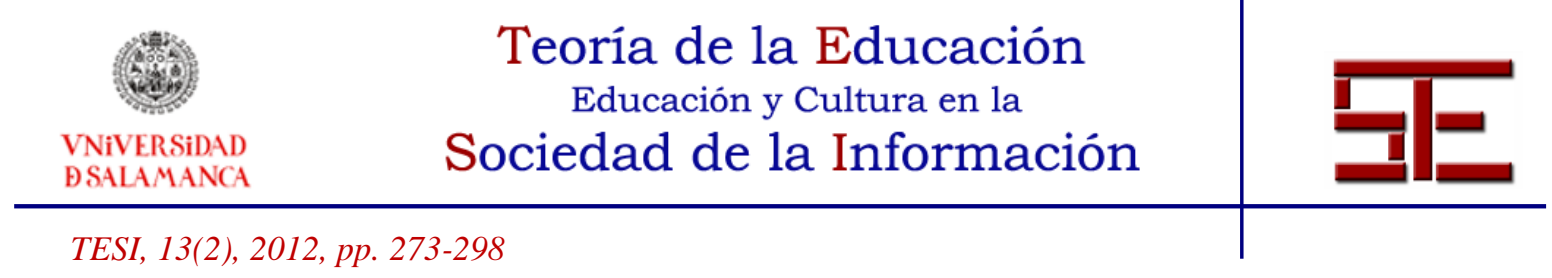

${ }^{12}$ Un atractor es un estado o tendencia que define un patrón fiable de cambios para el cual un sistema dinámico tiende a lo largo del tiempo, y al que regresa después de haber sido perturbado. Se puede decir que un atractor «atrae» la dinámica del sistema (Nowak, Vallacher y Zochowski, 2005) o ejerce su magnetismo sobre lo que le rodea (Roldán Castro, 1995). Existen distintos tipos de atractores (fijo, periódico, extraño).

Para citar el presente artículo puede utilizar la siguiente referencia:

Gonçalves, T. (2012). El sujeto neuronal: aportaciones para una pedagogía de la posibilidad. Revista Teoría de la Educación: Educación y Cultura en la Sociedad de la Información. 13(2), 273-298 [Fecha de consulta: dd/mm/aaaa]. http://campus.usal.es/ revistas_trabajo/index.php/revistatesi/article/view/9009/9253 